\title{
Detailed Dual-Doppler Structure of Kelvin-Helmholtz Waves from an Airborne Profiling Radar over Complex Terrain. Part II: Evidence for Precipitation Enhancement from Observations and Modeling
}

\author{
Coltin Grasmick, ${ }^{\mathrm{a}}$ Bart Geerts, ${ }^{\mathrm{a}}{ }^{\mathrm{Xia}}$ Chu, ${ }^{\mathrm{a}}$ Jeffrey R. French, ${ }^{\mathrm{a}}$ And Robert M. Rauber ${ }^{\mathrm{b}}$ \\ a Department of Atmospheric Sciences, University of Wyoming, Laramie, Wyoming \\ ${ }^{\mathrm{b}}$ Department of Atmospheric Sciences, University of Illinois at Urbana-Champaign, Urbana, Illinois
}

(Manuscript received 27 December 2020, in final form 13 July 2021)

\begin{abstract}
Kelvin-Helmholtz $(\mathrm{KH})$ waves are a frequent source of turbulence in stratiform precipitation systems over mountainous terrain. $\mathrm{KH}$ waves introduce large eddies into otherwise laminar flow, with updrafts and downdrafts generating small-scale turbulence. When they occur in cloud, such dynamics influence microphysical processes that impact precipitation growth and fallout. Part I of this paper used dual-Doppler, 2D wind and reflectivity measurements from an airborne cloud radar to demonstrate the occurrence of $\mathrm{KH}$ waves in stratiform orographic precipitation systems and identified four mechanisms for triggering $\mathrm{KH}$ waves. In Part II, we use similar observations to explore the effects of $\mathrm{KH}$ wave updrafts and turbulence on cloud microphysics. Measurements within KH wave updrafts reveal the production of liquid water in otherwise ice-dominated clouds, which can contribute to snow generation or enhancement via depositional and accretional growth. Fallstreaks beneath $\mathrm{KH}$ waves contain higher ice water content, composed of larger and more numerous ice particles, suggesting that $\mathrm{KH}$ waves and associated turbulence may also increase ice nucleation. A large-eddy simulation (LES), designed to model the microphysical response to the $\mathrm{KH}$ wave eddies in mixed-phase cloud, shows that depositional and accretional growth can be enhanced in $\mathrm{KH}$ waves, resulting in more precipitation when compared to a baseline simulation. While sublimation and evaporation occur in $\mathrm{KH}$ downdrafts, persistent supersaturation with respect to ice allows for a net increase in ice mass. These modeling results and observations suggest that $\mathrm{KH}$ waves embedded in mixed-phase stratiform clouds may increase precipitation, although the quantitative impact remains uncertain.
\end{abstract}

SIGNIFICANCE STATEMENT: This study investigates how the turbulence caused by Kelvin-Helmholtz (KH) waves embedded in deep clouds affect precipitation growth. To answer this question, we used a Doppler radar on board a research aircraft to locate KH waves inside of clouds. These waves often break, and produce fallstreaks, which may descend down to the surface. Aircraft measurements from within these fallstreaks confirmed that they contain larger, more numerous ice particles. This evidence of enhanced precipitation coincided with turbulence and supercooled liquid water produced by the $\mathrm{KH}$ waves. Modeled $\mathrm{KH}$ waves show that some of the precipitation enhancement is caused by accretion and deposition within updrafts, but further research is needed to understand the role of turbulence and ice initiation in $\mathrm{KH}$ waves.

KEYWORDS: Eddies; Gravity waves; Kelvin-Helmholtz instabilities; Mountain waves; Orographic effects; Turbulence; Vertical motion; Wave breaking; Waves, atmospheric; Wind shear; Snowfall; Radars/Radar observations; Remote sensing; Large eddy simulations

\section{Introduction}

The importance of small-scale turbulence (i.e., turbulence at the scale of the typical spacing between hydrometeors) in precipitation processes is well recognized, both in warm clouds (e.g., Pinsky et al. 1999, 2000; Grabowski and Wang 2013; Chen et al. 2016) and in mixed-phase clouds (e.g., Pinsky and Khain 1998; Korolev et al. 2017), enhancing such processes as collision-coalescence, aggregation, and accretion. In contrast, there has been little work investigating the impact of larger, cloud-scale turbulence consisting of turbulent features that span the length of a cloud. Cloud-scale turbulence often takes the form of eddies, such as those associated with shear-driven Kelvin-Helmholtz $(\mathrm{KH})$ billows, due to the dynamics that drive turbulence at this scale and compensating up or downdrafts. The key microphysical mechanisms within large eddies

Corresponding author: Coltin Grasmick, cgrasmic@uwyo.edu are related not just to turbulence, but also to transient updrafts, which may induce rapid, significant changes in temperature and supersaturation.

One process that appears to be strongly affected by largeeddy turbulent motions is ice initiation (Mazin 1986; Rauber and Tokay 1991). Airborne in situ and Wyoming Cloud Radar (WCR) observations in the Profiling of Winter Storms (PLOWS) campaign revealed the common presence of regularly spaced convective downdrafts alternating with narrow, strong updrafts near the tops of deep stratiform clouds, as a result of cloud-top radiative cooling (Rauber et al. 2014, 2015; Rosenow et al. 2014). Ice particles often initiate in these cloud-top "generating cells," presumably due to local supersaturation and/or turbulence (Keeler et al. 2016) resulting in fallstreaks of enhanced reflectivity (Plummer et al. 2015).

Large KH eddies may also be important in collisioncoalescence growth of drops and in accretional and aggregational growth of snow (Houze and Medina 2005; Medina and 
(a) SNOWIE IOPS

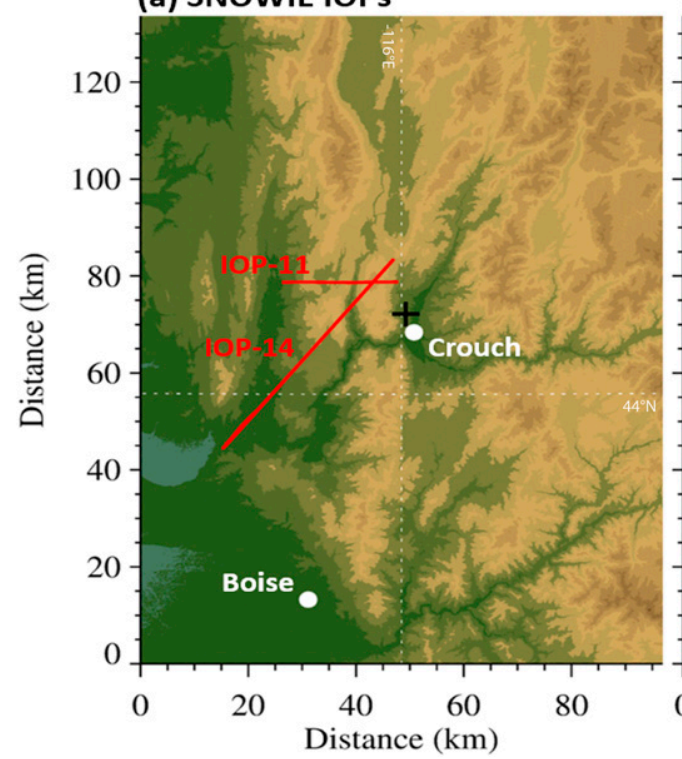

(b) CAMPS IOPs

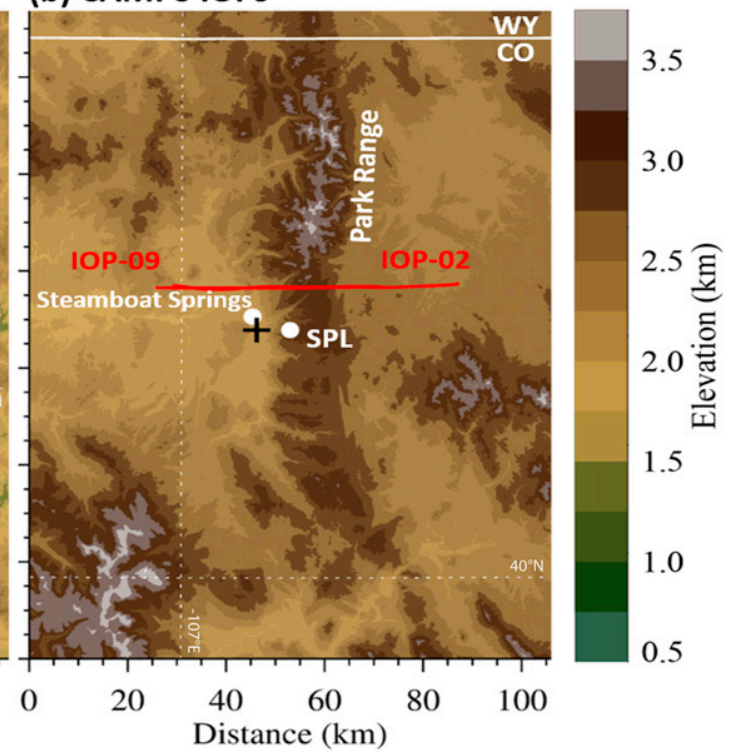

FIG. 1. Topographic maps containing the flight legs during the (a) SNOWIE and (b) CAMPS IOPs. Red lines indicate the relevant flight tracks for each IOP. Black crosses show the location of radiosonde launches. White labels indicate locations or ranges mentioned in the text [Storm Peak Laboratory (SPL)]. The flight path of CAMPS IOP-02 and IOP-09 were nearly the same.

Houze 2015; Barnes et al. 2018). The first two papers refer to "overturning cells," presumably KH billows, with size characteristics (1-3-km spacing) similar to those documented in Grasmick and Geerts (2020, hereafter Part I). Barnes et al. (2018) shows evidence of enhanced accretion and aggregation within KH waves. Conrick et al. (2018) numerically recreate such shear-driven waves and confirm that $\mathrm{KH}$ waves may enhance snow growth by deposition, accretion, and aggregation.

In Part I, airborne cloud radar data were used to reveal that $\mathrm{KH}$ waves are common in stratiform clouds over complex terrain and that the associated updrafts exceed the typical fall speed of snow over a depth of several hundreds of meters. Furthermore, dual-Doppler radar observations evinced the general kinematic/dynamic behavior of $\mathrm{KH}$ waves trains. The 2D, dual-Doppler transects showed that across-mountain flow produces local enhancements of vertical wind shear, which can lead to $\mathrm{KH}$ instability. The layer of dynamic overturning in $\mathrm{KH}$ wave trains (shown schematically in Fig. 10 in Part I) is contained within the shear layer and is characterized by strong upand downdrafts and fine-scale turbulence. Above and below this layer, air, perturbed by the KH billows, excites gravity waves with more laminar up- and downdrafts. When this instability is terrain driven, any resulting $\mathrm{KH}$ wave trains are quasi stationary with respect to the terrain. Ascent and crossmountain variations in shear due to vertically propagating terrain-driven waves are invariably coupled, explaining the common occurrence of $\mathrm{KH}$ wave trains in orographic clouds.

In Part I, the presence of cloud and precipitation was merely a convenience, i.e., for the radar to detect the KH wave kinematics. The objective of this study (Part II) is to answer the question of whether in-cloud $\mathrm{KH}$ waves can substantially alter cloud processes and precipitation growth using airborne in situ and radar observations. Since these observations do not quantify water mass conversions, we also employ a simple large-eddy simulation (LES) to demonstrate the impact of $\mathrm{KH}$ waves on water-phase conversions in cloud, and on precipitation.

This paper is organized as follows. The observational methods are presented in section 2. Section 3 presents airborne measurements at and below the level of KH wave trains. Section 4 compares the WCR observations of precipitation enhancement to results from an idealized 100-m-resolution LES. This is followed by a discussion in section 5 and conclusions in section 6 .

\section{Data and observational methods}

\section{a. The SNOWIE and CAMPS campaigns}

The data presented here were collected in two field campaigns that used the University of Wyoming King Air (UWKA) research aircraft (Fig. 1). The Seeded and Natural Orographic Wintertime clouds: the Idaho Experiment (SNOWIE; 2017), yielded 24 intensive observation periods (IOPs) over the Payette basin of western Idaho (Tessendorf et al. 2019). More than half of the IOPs had occurrences of in-cloud $\mathrm{KH}$ waves, identified by their distinguishing kinematic pattern (Part I) in cross sections of vertical velocity from the airborne WCR. The SNOWIE campaign did not target $\mathrm{KH}$ waves. These waves were encountered by chance, and this study was motivated by these chance observations of WCR-detected $\mathrm{KH}$ waves and, in some cases, associated plumes of enhanced radar reflectivity.

The mountains in the SNOWIE domain are highly complex; many peaks and valleys are present below the UWKA flight 
tracks. In contrast, the terrain in the Colorado Airborne MultiPhase Cloud Study (CAMPS; 2011) domain has a single prominent ridgeline. This ridgeline, the Park Range, is located in northern Colorado just east of Steamboat Springs. The CAMPS campaign conducted 29 IOPs and, like SNOWIE, frequently revealed vertical velocities associated with $\mathrm{KH}$ wave trains.

\section{b. The Wyoming Cloud Radar}

The WCR is a Doppler radar operating at 3-mm wavelength and deployed on the UWKA (Wang et al. 2012; University of Wyoming Research Flight Center 1995). During SNOWIE and CAMPS, the WCR measured the equivalent reflectivity factor (hereafter reflectivity), and hydrometeor radial velocity with three fixed antennas pointing up (near-zenith), down (nearnadir), and down-forward ( $\sim 30^{\circ}$ forward of nadir). The nominal range resolution of the WCR as operated during SNOWIE and CAMPS is approximately $37.5 \mathrm{~m}$ with a beamwidth of $0.7^{\circ}$ and a sampling rate of $0.045 \mathrm{~s}\left(4.5 \mathrm{~m}\right.$ when flying $\left.100 \mathrm{~m} \mathrm{~s}^{-1}\right)$, making it ideal for studying fine-scale (on the order of a few tens of meters) in-cloud features like $\mathrm{KH}$ waves.

WCR-measured radial velocity along a quasi-vertical beam is composed of hydrometeor vertical velocity (air vertical motion and particle fall speed), aircraft motion along the beam radial, and horizontal wind "contamination" due to the nonvertical orientation of the radar beam arising from a fixed beam and exacerbated by aircraft attitude fluctuations (mainly roll and pitch). The data herein have been processed to account for these components to estimate true hydrometeor vertical velocity as follows. For both CAMPS and SNOWIE, the known 3D beam orientation is used to first remove aircraft motion (Haimov and Rodi 2013). Then, by using wind measurements from a nearby sounding and estimates of the WCR beam pointing angles, the horizontal wind contamination is estimated and removed following Geerts and Miao (2005), Miao et al. (2006), and Bergmaier and Geerts (2016). Radiosonde balloons were launched from Crouch, Idaho, and Steamboat Springs, Colorado, for SNOWIE and CAMPS IOPs, respectively (black crosses in Fig. 1), and are used as an estimate of the horizontal wind.

The final step to estimate the vertical air motion is to extract the hydrometeor fall speed from the hydrometeor vertical velocity. In CAMPS, the estimated flight-level hydrometeor fall speed is removed by comparing WCR velocity close to the aircraft (within $150 \mathrm{~m}$ of the aircraft, using close-gate data from zenith and nadir beams), with the air vertical velocity measured by the gust probe on the UWKA. The difference (the hydrometeor fall speed) is computed for each straight and level flight leg and is assumed to apply at all heights. This is a crude estimation, although, given that optical array probes at flight level revealed little particle accretion, the clouds were stratiform, and precipitation fell as snow down to ground level, fall speed variations should be small. The flight-level leg-mean fall speed was close to $1 \mathrm{~m} \mathrm{~s}^{-1}$ for all flight legs, decreasing slightly with increasing altitude or toward cloud edge. In SNOWIE, a further correction is possible because the UWKA flew repeated fixed flight legs in opposite directions (Geerts and Miao 2005). The average difference in vertical velocity between opposing pairs of flight legs is measurement error introduced by unaccounted-for beam angles (mainly in the along-track direction, i.e., pitch) and can be split between the two legs, assuming the mean gust-probe air vertical motion over the full flight leg can be extended from flight level (T. J. Zaremba et al. 2021, unpublished manuscript). Uncertainty in the estimated air vertical motion from errors in fall speed, beam pointing angles, and horizontal wind contamination is approximately $1 \mathrm{~m} \mathrm{~s}^{-1}$.

By combining the nadir and down-forward beams, dualDoppler synthesis is used to derive the 2D wind field (along track, vertical) in a vertical plane below the UWKA (Damiani and Haimov 2006; Geerts et al. 2006). Because the UWKA flew roughly parallel with the mean wind, the resulting along-track wind speed information is close to the actual horizontal wind. This is especially useful for identifying layers of strong vertical shear that spawn KH wave instability. For additional discussion on the operating principles, processing, and errors of the dual-Doppler synthesis, the reader is referred to Part I.

\section{c. In situ microphysics observations}

Several in situ probes are used to characterize cloud and hydrometeor properties. The forward-scattering Cloud Droplet Probe (CDP; Lance et al. 2010) and two optical array probes (OAP) are used together to estimate particle size distributions from a few microns to several millimeters. The CDP provides a measure of particle diameter based on a forward-scattering technique assuming liquid water spheres. Particles are sized in discreet bins from 2 to $50 \mu \mathrm{m}$ in diameter. The two OAPs [2DStereo Probe (2DS) and the legacy 2D Precipitation Probe (2DP)] capture images of particles as they pass through a columnated laser, providing additional information such as particle shape. The 2DS (Lawson et al. 2006) is capable of measuring particles from about 10 to $1280 \mu \mathrm{m}$ with $10-\mu \mathrm{m}$ resolution and the 2DP measures particles from about 400 to $1600 \mu \mathrm{m}$ with $200-\mu \mathrm{m}$ resolution. Data from the OAPs are processed using the University of Illinois OAP Processing Software (Jackson and McFarquhar 2014; Finlon et al. 2016), which filters out image artifacts and applies dimension corrections. Processed data from the three probes are combined to provide a continuous size distribution for diameters ranging from $2 \mu \mathrm{m}$ to $16 \mathrm{~mm}$. During the cases from the 2011 CAMPS campaign, the 2DS was not installed on the UWKA and a 2D probe sampling the same size range had data quality issues. For these cases, the particle size information was limited to $(2-50 \mu \mathrm{m})$ and $(0.4-16 \mathrm{~mm})$.

During SNOWIE, the Nevzorov hot wire probe (Korolev et al. 1998) provided a measurement of liquid water content (LWC) as well as total water content (TWC) from a heated cone. For an estimate of LWC during CAMPS, we resort to a volume estimate from the CDP, assuming that the scattering particles are liquid spheres.

\section{d. Idealized WRF LES}

To better understand the microphysical processes occurring within $\mathrm{KH}$ waves, we designed an idealized WRF simulation in LES mode (Moeng 1984). Here we use WRF v3.3.1 with the WRF LES Statistics Package (LESSP; Yamaguchi and Feingold 2012). An elongated domain containing 2560 (in $x$ ) $\times 32$ (in $y$ ) grid points with $100-\mathrm{m}$ horizontal resolution is used to allow 
westerly wind shear to develop $\mathrm{KH}$ waves. The model top is set at $15 \mathrm{~km}$ with a damping layer of $5 \mathrm{~km}$. There are 138 levels, with grid spacing evenly distributed from the surface to $\sim 5 \mathrm{~km}$ at $\sim 50$-m interval. Above $5 \mathrm{~km}$, the vertical grid spacing increases exponentially. Periodic boundary conditions are applied across the two lateral boundaries in the $y$ direction. There is no perturbation in the $y$ direction; thus, it is basically a 2D simulation. We focus on the development of $\mathrm{KH}$ waves aloft (above the boundary layer), so the surface scheme is turned off with freeslip surface. The Thompson bulk cloud microphysics scheme is used (Thompson et al. 2008). Subgrid-scale turbulent exchange processes are represented through a 1.5-order TKE closure scheme. Shortwave and longwave radiation schemes and surface heat fluxes are switched off in order to simplify the problem and suppress any buoyancy-driven coherent boundary layer circulations that otherwise may have developed.

\section{KH wave cases investigated using WCR and/or in situ measurements}

Plumes of enhanced reflectivity, or fallstreaks, are evidence of locally enhanced hydrometeor growth and fallout. They are observed in various naturally precipitating systems (e.g., Kalesse et al. 2016; Murphy et al. 2017; Keppas et al. 2018) and can be man-made as well, e.g., by the introduction of ice nucleating particles in a supercooled liquid cloud (French et al. 2018; Tessendorf et al. 2019; Friedrich et al. 2020). Convection embedded in deep stratiform systems and cloud-top generating cells (e.g., Plummer et al. 2015) frequently produce fallstreaks. Fallstreaks are also observed descending from regions of overturning $\mathrm{KH}$ waves as illustrated, for example, in Fig. 2 and described below. Fallstreaks provide strong evidence for an impact of $\mathrm{KH}$ waves on microphysics in deep stratiform clouds. We provide four examples of enhanced reflectivity associated with $\mathrm{KH}$ waves (three of which have clear fallstreaks), as documented by the WCR in mixed-phase clouds above the freezing level. For those cases with a suitable flight level, we examine in situ cloud probe data to investigate how $\mathrm{KH}$ waves and turbulence affect cloud microphysical processes.

\section{a. Case 1: Fallstreaks intersecting the surface and dual-Doppler analysis}

The first case from CAMPS IOP-02 (20 December 2010) contains multiple layers of $\mathrm{KH}$ waves below flight level (the top of each panel). It is presented to fully illustrate the salient $\mathrm{KH}$ wave dynamics (described in Part I) and show the near-surface reflectivity (and thus precipitation) increase caused by the $\mathrm{KH}$ wave fallstreaks. The focus of our discussion is on the lowerlevel $\mathrm{KH}$ waves with fallstreaks that can be traced from their origin within a shear layer down to the surface (indicated in Fig. 2). The upper layer of turbulence and gravity waves is presumably from $\mathrm{KH}$ waves that have decayed, as overturning billows are not distinct and the reflectivity enhancement more diffuse. Sounding data from a balloon, released simultaneously, west of the Park Range (see Fig. 1b), are shown in the left column of Fig. 2. They reveal a well-capped, stagnant cold pool contained just below mountain-top level, such that the strong flow above the inversion hardly "felt" the mountain, i.e., the Park Range did not sustain significant vertically propagating gravity waves. The vertical velocity pattern we identify as $\mathrm{KH}$ waves (see Part I) originates in a layer of strong shear between 3 and $4 \mathrm{~km}$ MSL (Fig. 2d) where the Richardson number is low (small panel next to Fig. 2b). Because flight level is much higher than the observed fallstreaks, reflectivity is the only source of microphysics data; however, the high flight track allows for the derivation of along-track wind speed $U$ and wind shear $(d U / d z)$ through dual-Doppler synthesis (as described in Part I) (Figs. 2c,d).

In this case, the main fallstreaks form at around $-20^{\circ} \mathrm{C}$. The most prominent fallstreak descends from an overturning billow directly above the highest terrain. There also appears to be aged fallstreaks downwind of the highest terrain. The upper part of this KH overturning layer is well mixed in $\theta_{e}$, in fact, the sounding reveals some potential instability just below $5 \mathrm{~km}$ MSL (Fig. 2, top-left insert), suggesting that the KH motions may have recently released some convective motions over a very limited depth above the wave layer. The fallstreaks deform by shear as they descend into and seed the shallow, stagnant, humid cold pool. This case is reminiscent of the overturning cells in the shear layer on top of flow blocked by the Sierra Nevada described in Houze and Medina (2005) and Medina and Houze (2015). Periodic KH waves such as these may produce periods of enhanced snowfall, similar to the oscillations in drop size and rain rate observed by Barnes et al. (2018) upstream of the Olympic Mountains.

As seen in this cross section, $\mathrm{KH}$ waves are a source of turbulence in stratiform precipitation systems. We identify turbulence by using energy dissipation rate (EDR; Fig. 2e) derived from WCR vertical velocity. The derivation of EDR from the WCR vertical velocity field is discussed in Part I. EDR values peak in locations of $\mathrm{KH}$ wave activity but are generally large along the two shear layers. A comparison between EDR and WCR reflectivity (Figs. 2a,e) reveals that the largest increases in reflectivity occur directly beneath the largest EDR values. The average profiles of EDR and reflectivity for the cross section (panel to the left of Fig. 2e) also show this relationship. Reflectivity increases most rapidly across the upper high-EDR layer, near $z=6.4 \mathrm{~km} \mathrm{MSL}$, where the temperature is about $-25^{\circ} \mathrm{C}$. Reflectivity also increases beneath the primary $\mathrm{KH}$ waves although the effects are broader due to their limited horizontal extent and the variation of their vertical location.

Within turbulence, particles of different inertia develop relative velocity to one another. This is especially true for a population of particles with large variations in fall speed and inertia like in mixed-phase clouds with both ice crystals and liquid droplets (Pinsky and Khain 1998). The resulting increase in relative velocity within a turbulent, mixed-phase cloud, produces many more particle collisions (Grabowski and Wang 2013; Chen et al. 2016). For a particle with larger inertia (e.g., rimed ice), turbulence increases the swept volume which, if containing many small droplets, accrete and increase ice mass, and thus radar reflectivity (Geerts et al. 2011). Next, we present flight-level measurements of KH wave penetrations in SNOWIE and CAMPS, first showing that liquid can be introduced via $\mathrm{KH}$ wave updrafts. We examine flight tracks at the level of $\mathrm{KH}$ 


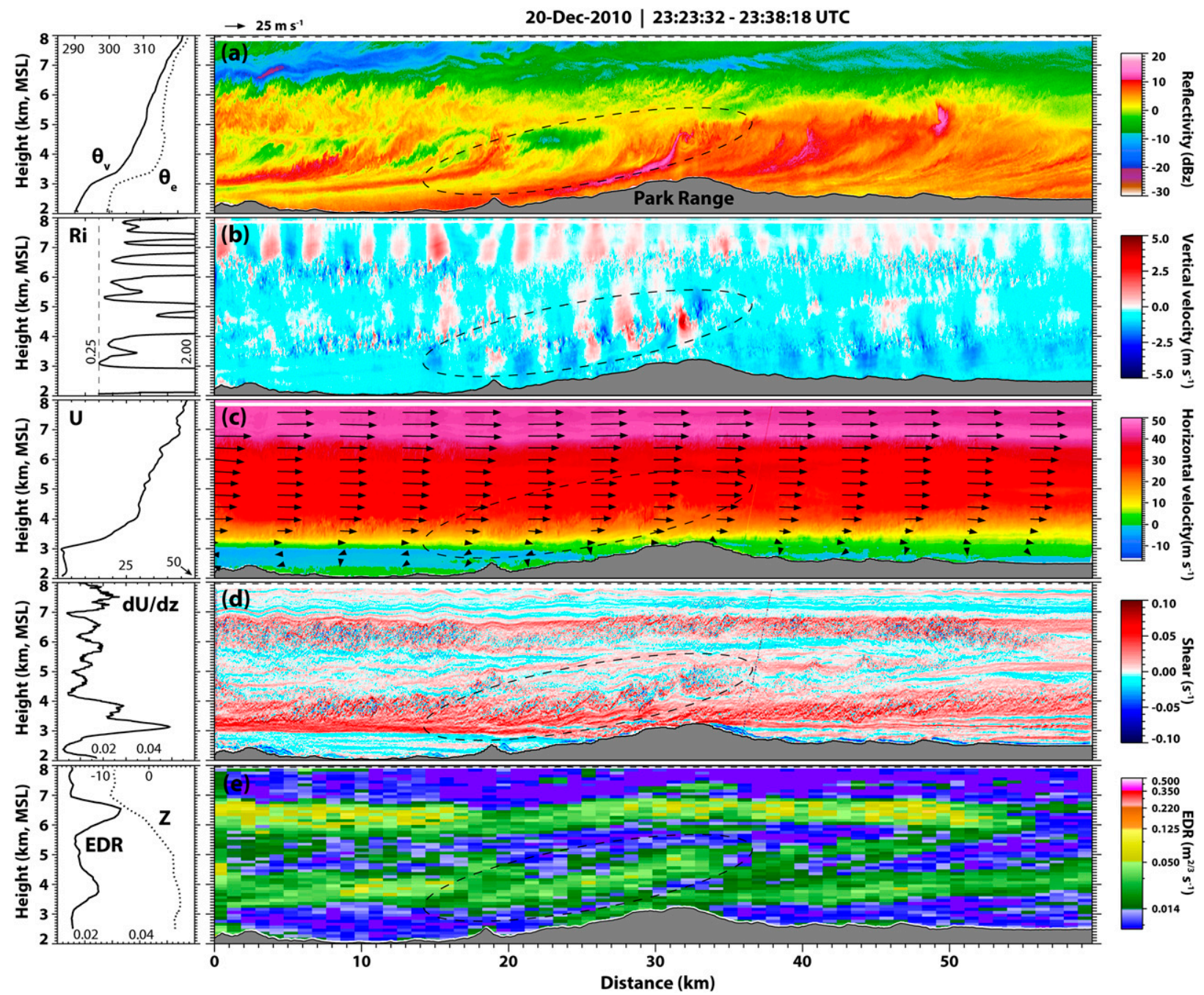

FIG. 2. (a) WCR reflectivity and (b) Doppler vertical velocity for a case of KH waves in CAMPS IOP-02 on 20 Dec 2010. (c),(d) DualDoppler synthesis to determine the along-track wind component and vertical shear with arrows that show the 2D wind field. (e) The EDR derived from WCR vertical velocity. (left, first to fourth rows) Variables derived from data from a radiosonde launched at 2237 UTC in Steamboat Springs (Fig. 1b), i.e., virtual and equivalent potential temperature (K), Richardson number, along-track wind speed ( $\mathrm{m} \mathrm{s}^{-1}$ ), and along-track wind shear $\left(\mathrm{s}^{-1}\right)$, respectively. (bottom left) Leg-average profiles of EDR (solid, bottom axis) and reflectivity (dotted, top axis).

waves, and then below the $\mathrm{KH}$ waves, in the emerging fallstreaks, to observe the resulting microphysics.

\section{b. Case 2: Billow microphysics}

During CAMPS IOP-09 on 19 January 2011, the UWKA sampled a stratified prefrontal system crossing the Park Range in Colorado. This precipitation system was layered, with a synoptic-scale upper-level cloud and an orographic low-level cloud. Such layered structure is common when frontal systems cross mountains (e.g., Herzegh and Hobbs 1980; Choularton and Perry 1986). The upper and lower layers often connect over mountains (Tessendorf et al. 2019), as they do here, i.e., the WCR revealed ice crystals falling from the continuous upper layer into the lower layer over the Park Range (Fig. 3a).
The WCR observes a large train of KH waves centered over the Park Range (Fig. 3b, dashed rectangle). WCR reflectivity and velocity depict a classic billow structure representative of $\mathrm{KH}$ waves. Close proximity sounding data (not shown) reveal a layer of shear and low Richardson number matching the height of the observed waves. The wave train spans about $20 \mathrm{~km}$ and individual waves have a wavelength of about $2.2 \mathrm{~km}$. The UWKA, flying at $5.2 \mathrm{~km}$ MSL, passes through the top of the KH billows and skims the top of the turbulent layer (Fig. 3b). As is common during cross-mountain flow over the Park Range, a terrain-driven vertically propagating gravity wave is present, superimposed on the $\mathrm{KH}$ waves; substantial upward velocity is apparent above the windward slope between 7 and $17 \mathrm{~km}$ while downward motion exists above the lee slope between 17 and $27 \mathrm{~km}$. 

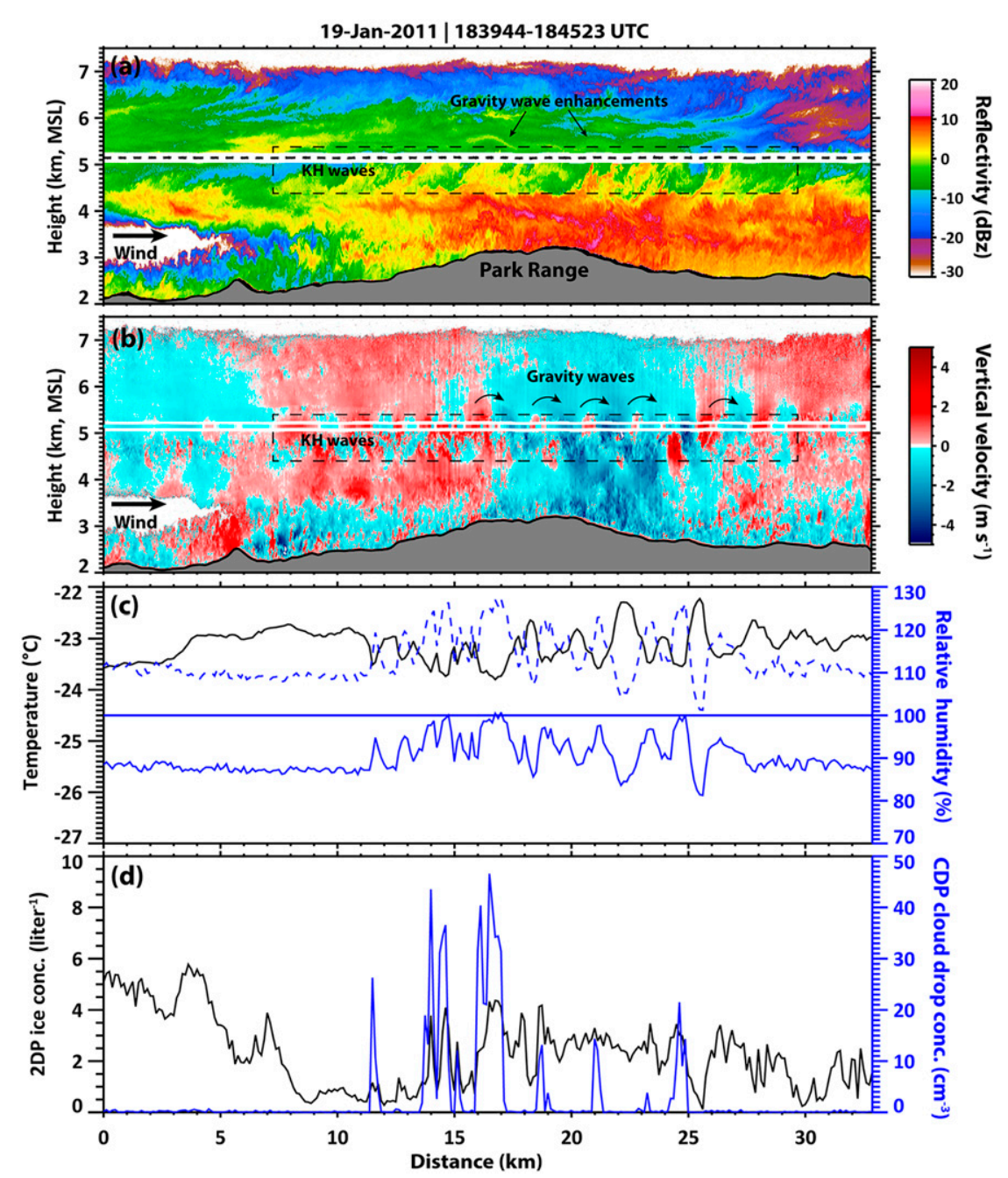

FIG. 3. WCR and in situ observations through a train of KH waves during CAMPS IOP-09 on 19 Jan 2011. Panels include WCR (a) reflectivity and (b) estimated air vertical velocity and flight-level (c) temperature (black), relative humidity (blue solid line-relative to liquid; blue dashed line-relative to ice), (d) ice concentration (black), and droplet concentration (blue). In (b), the air vertical velocity measured by the gust probe is shown at flight level, using the same color scale. In this and all other WCR transects, the flow is from left to right as indicated by the arrow. The dashed rectangle contains the region with overturning $\mathrm{KH}$ billows and the curved arrows indicate the gravity waves mentioned in the text.

The vertical velocity field displays a pattern characteristic of a KH wave train (see Part I), and the reflectivity (Fig. 3a) reveals the distortions created by the KH billows. The flow field appears quite turbulent (Fig. 3b), resulting in reflectivity distortions that are often tenuous or fragmented. Snow growth appears to be driven primarily by the mesoscale gravity wave, along the windward slope of the Park Range, in the dendritic growth zone $\left(-12^{\circ}\right.$ to $-18^{\circ} \mathrm{C}$ temperature range, corresponding to $3.5-4.2 \mathrm{~km}$ MSL in this case, according to a nearby sounding, not shown). The question is whether the smaller-scale $\mathrm{KH}$ waves merely distort the snow (reflectivity) field, or also impact snow growth.

In situ observations record perturbations in kinematics (vertical velocity; Fig. 3b), thermodynamics (temperature, relative humidity; Fig. 3c), and microphysics (ice concentration, cloud droplet concentration; Fig. 3d). Because of uncertainties with measuring relative humidity at cold temperatures, vapor pressure (measured by a LICOR7000 probe) is adjusted so that the relative humidity over liquid reaches $100 \%$ where cloud droplets are observed by the CDP.

CDP and 2DP measurements show that this cloud is dominated by ice and nearly devoid of liquid water at temperatures around $-24^{\circ}$ to $-22^{\circ} \mathrm{C}$ (Figs. 3c,d). The only exception to an ice-only cloud is in the proximity of strong $\mathrm{KH}$ wave updrafts. Here, droplets at concentrations up to $50 \mathrm{~cm}^{-3}$ are situated in the parcel crests, i.e., between updrafts and downdrafts where parcels reach their maximum height. This liquid results during 
the phase relaxation time for ice deposition (Korolev 1995; Korolev and Mazin 2003) because liquid-relative supersaturation increases while the existing ice is unable to grow by deposition (removing water vapor and reducing saturation) at the same rate: the observed $\mathrm{KH}$ wave updrafts in this environment produce a calculated supersaturation $(S)$ change of $\sim 1.4 \times 10^{-3} \mathrm{~s}^{-1}$, corresponding with a condensation rate of $\sim 1.2 \times 10^{-6} \mathrm{~kg} \mathrm{~kg}^{-1} \mathrm{~s}^{-1}$. Observations of ice particle concentrations, median size, and ice supersaturation values suggest a vapor deposition rate at least an order of magnitude smaller in these updrafts (Rutledge and Hobbs 1983), causing interstitial cloud condensation nuclei $(\mathrm{CCN})$ to activate and increasing the number of cloud droplets (e.g., Majewski and French 2020). So, in this case, although the $\mathrm{KH}$ wave updrafts are much less extensive than the $20 \mathrm{~km}$ wavelength gravity waves, the rapid upward displacements in a $\mathrm{KH}$ wave enables brief periods of supersaturation in which liquid nucleates and grows by condensation, and ice nucleates and grows by deposition. The introduction of liquid into an ice-dominated cloud is important because it allows ice growth through additional processes such as accretion (Houser and Bluestein 2011), enhanced depositional growth via the Bergeron process (Bergeron 1935), and ice multiplication via rime splintering (Hallett and Mossop 1974), although rime splintering would not be active at the temperatures observed in this particular case.

Composite size distributions, compiled for regions of updrafts $\left(w>0.25 \mathrm{~m} \mathrm{~s}^{-1}\right)$ and downdrafts $\left(w<-0.25 \mathrm{~m} \mathrm{~s}^{-1}\right)$ show that these billows have an order of magnitude more cloud droplets than their adjacent downdrafts (Fig. $4, D<50 \mu \mathrm{m}$ ). ${ }^{1}$ The concentration (size) of ice crystals also increases within updrafts (although the changes are smaller) (Fig. 4b, $D>400 \mu \mathrm{m}$ ), corresponding with streaks of higher reflectivity (Fig. 3a).

In situ measurements such as relative humidity and ice concentration display positive perturbations that align with gravity wave crests. The $\sim 20$-km wavelength perturbations are removed by subtracting a moving box average for each variable with a width matching the $\mathrm{KH}$ wave wavelength $(2.2 \mathrm{~km})$. The results in Fig. 5 indicate the microphysical response within the upward moving KH billows. Specifically, higher concentrations of ice particles and droplets indicate ice initiation and droplet formation in billow updrafts. Because ice concentration is better matched (or correlated) with humidity rather than vertical velocity, it is unlikely that these measurements are due to advection alone. Rather than being advected from below and the maximum ice and liquid concentrations being within the center of the updraft plume, the maximum ice and liquid concentrations are at the end of the rapid upward motion, where maxima in vertical displacement, cooling, and relative humidity occur. The existence of a cloud microphysical response to the $\mathrm{KH}$ waves is further corroborated by the presence of liquid within updrafts which is absent in the rest of this cloud.

\footnotetext{
${ }^{1}$ The scatterers detected by the CDP are believed to be mostly or entirely droplets, since LWC values estimated from CDP size distribution integration reasonably matches the LWC estimated by the hot wire and the Rosemount icing probes in CAMPS.
}
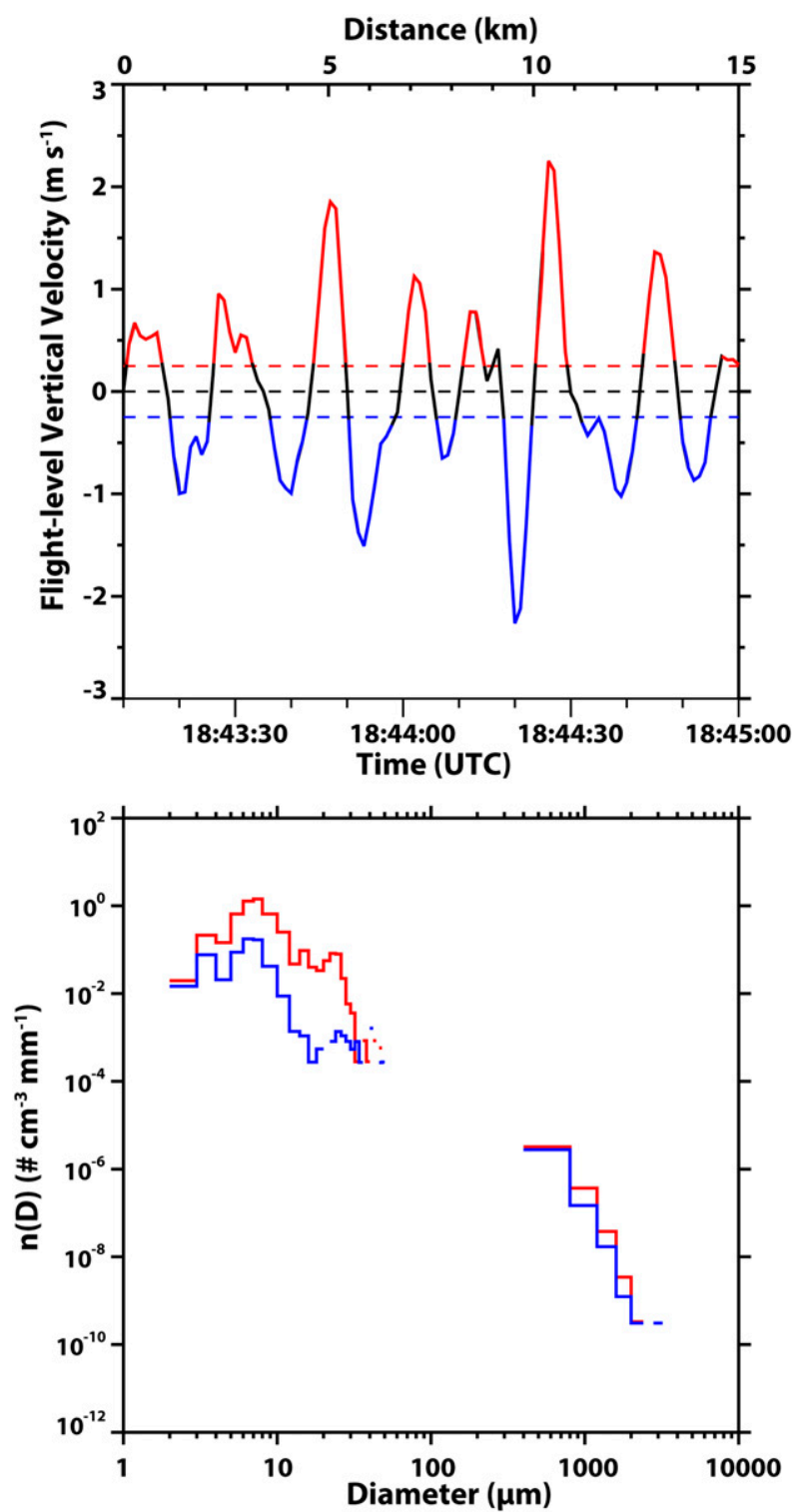

FIG. 4. (a) Smoothed vertical velocity, highlighting updraft (red) and downdraft (blue) regions for the KH billows analyzed in Fig. 3 and (b) composite particle size distributions for the corresponding red and blue regions.

Large eddies within $\mathrm{KH}$ billows likely produce competing factors affecting snow growth, similar to large eddies in a turbulent PBL (Chu et al. 2018). In their modeling study, Chu et al. (2018) used a similar set of idealized WRF large-eddy simulations to show the impacts of large-eddy turbulence in the PBL on snow growth. Turbulent motions within the cloud can enhance snow growth by the repeated creation of small areas of supersaturation (relative to water) resulting in enhanced accretional or depositional growth while, on the other hand, snow growth can be inhibited through turbulent entrainment of drier air from below cloud base (or aloft) into the cloud. In this case, the lack or absence of sublimation (Fig. 3c) (as the KH wave 

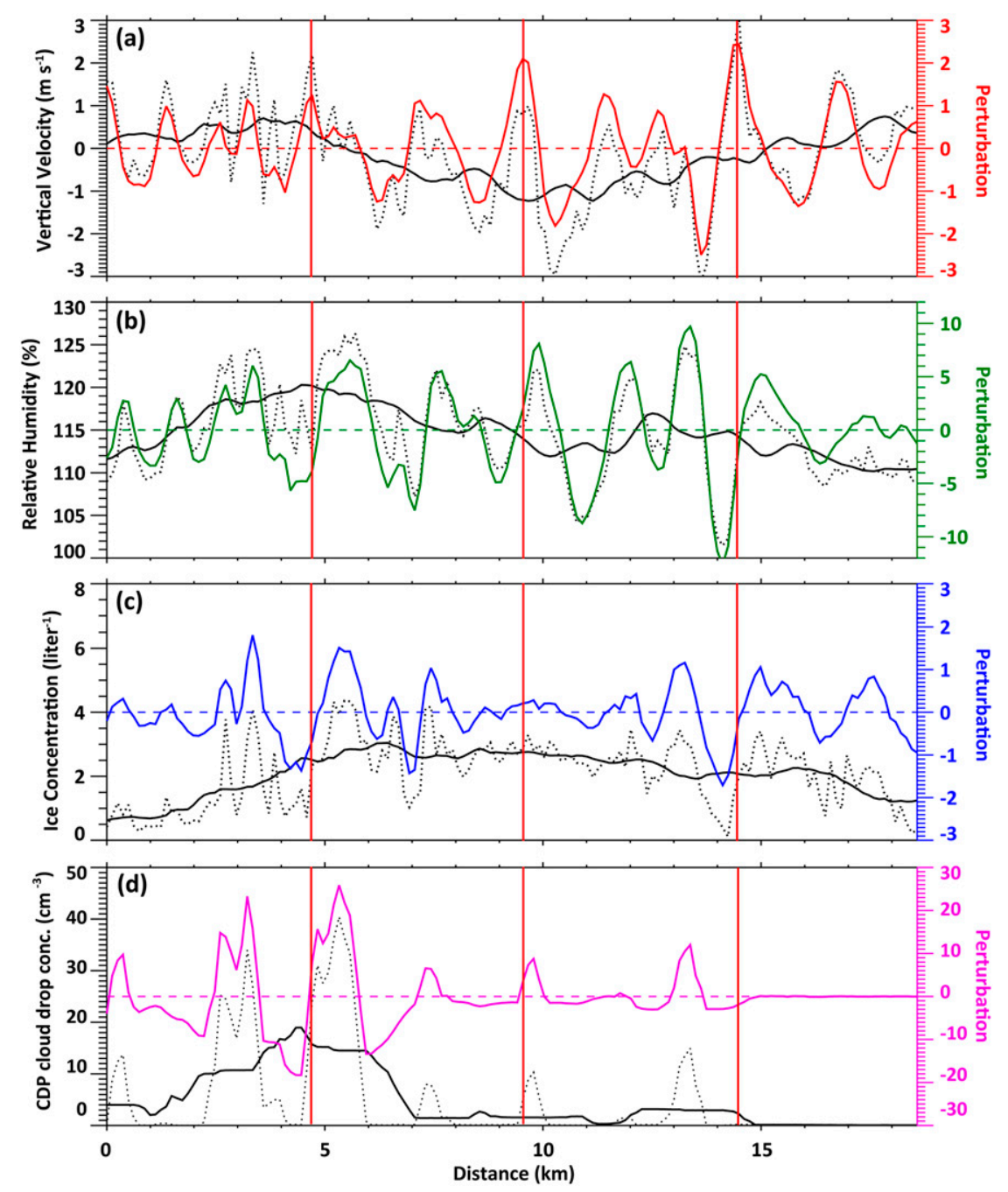

FIG. 5. In situ measurements of (a) vertical velocity, (b) relative humidity over ice, (c) ice concentration from the 2DP probe, and (d) cloud droplet concentration from the CDP probe. Dashed lines show original data, solid black lines show a $2.2-\mathrm{km}$ moving average, and colored lines and axes show the perturbation (original data minus moving average). Three prominent updrafts are delineated using vertical red lines for cross-panel comparisons.

train is embedded in a deep cloud) allows snow growth to dominate, as evident from increases in reflectivity beneath and downwind of the $\mathrm{KH}$ waves. At first thought, increasing the size of the KH wave eddies (by increasing the depth of the unstable shear layer) produces more liquid and increases the amount of cloud subject to possible turbulent enhancements. However, larger $\mathrm{KH}$ waves make the cloud more susceptible to entrainment and detrainment. Because of these effects, there is a point where further deepening of the $\mathrm{KH}$ wave layer may become detrimental to cloud longevity and precipitation.

In addition to the primary $\mathrm{KH}$ up- and down-drafts, smallscale gravity waves often exist above and below layers of $\mathrm{KH}$ waves, excited by the KH billows (Fig. 10 in Part I). These gravity waves, seen as variable downward motion in this case, evanesce above the $\mathrm{KH}$ waves. The velocity perturbations appear inconsequential when analyzed with reflectivity; there are vestiges of a thin band of enhanced reflectivity corresponding with the gravity waves (see pair of arrows immediately above flight level in Fig. 3a) but the enhancement does not appear to directly contribute to the high reflectivity values below flight level. Furthermore, this gravity wave reflectivity enhancement seems quite rare, not found in other cases.

\section{c. Case 3: Flight-level fallstreaks}

This example, from SNOWIE IOP-14 on 18 February 2017, was chosen because fallstreaks can be tracked downwind beginning from the level of $\mathrm{KH}$ waves in a series of five consecutive flight transects over the same terrain. Four of these transects are shown in Fig. 4 of Part I along with radiosonde 

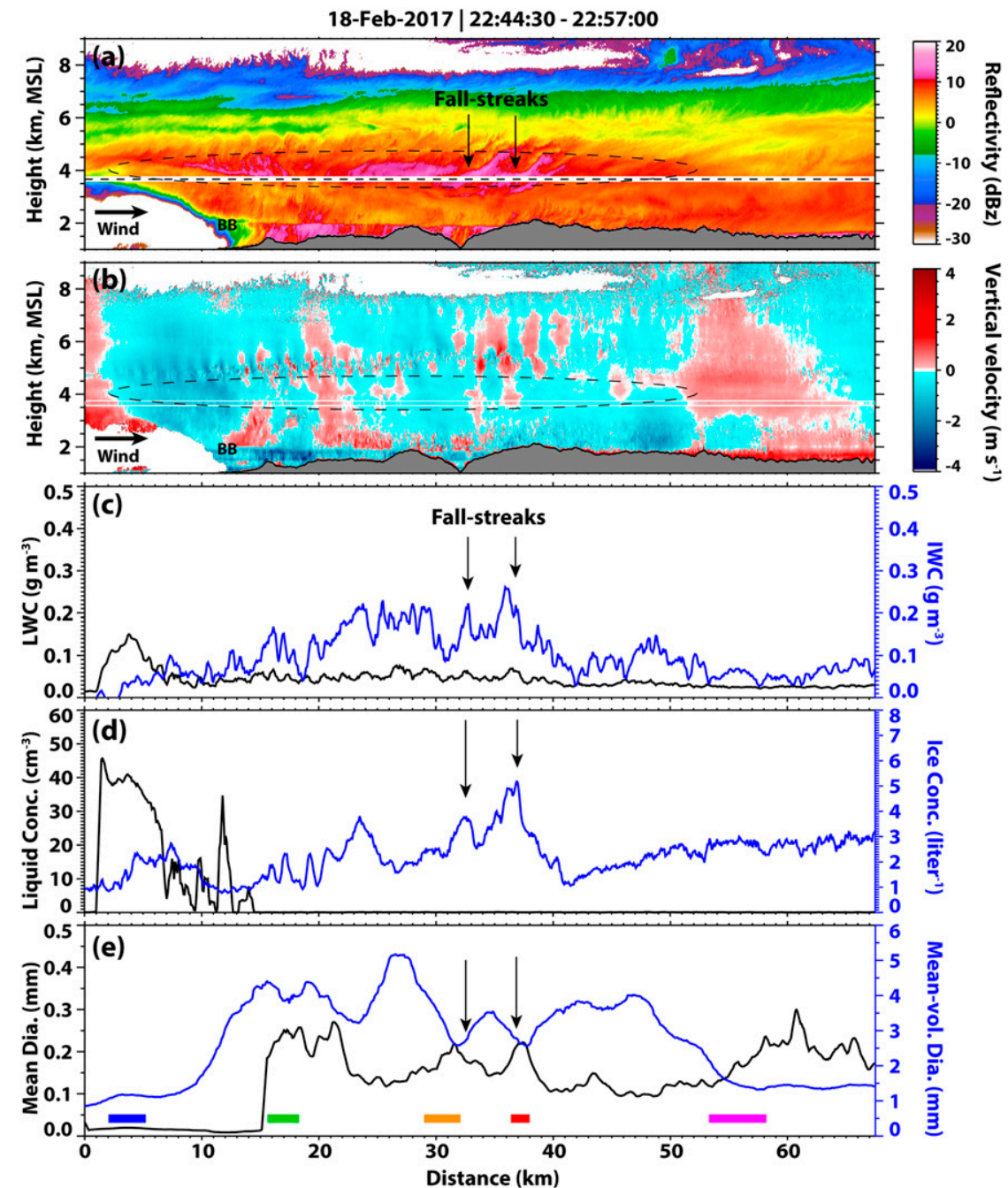

FIG. 6. (a) Reflectivity and (b) vertical velocity as in Fig. 3, but for SNOWIE IOP-14 on 18 Feb 2017. The in situ observations include (c) liquid water content and ice water content from the Nevzorov probe, (d) liquid drop concentration and ice particle concentration from the CDP and 2DP, and (e) mean diameter and mean-volume diameter derived from size distributions. In (a) and (b), the dashed oval contour marks the region of enhanced reflectivity below the $\mathrm{KH}$ waves and "BB" marks the left edge of the bright band. Colored bars at the bottom of (e) match with regions of 2DS images in Fig. 7.

data matching the $\mathrm{KH}$ waves to a critical Richardson layer. Here we display one of these transects (leg 2), where the UWKA flew through two distinct fallstreaks (Fig. 6). Some 2025 min earlier, a $\mathrm{KH}$ wave train was present upwind of these two fallstreaks (leg 1, shown in Fig. 4 in Part I). KH instability has been released in the shear layer between $10<x<45 \mathrm{~km}$ along track, at a height of about $5 \mathrm{~km} \mathrm{MSL}$, which is about $1.3 \mathrm{~km}$ above flight level, where the temperature is about $-9^{\circ} \mathrm{C}$ (Part I). As in the previous case, this cloud is mostly ice but regions of upward vertical velocity result in the formation of liquid droplets (e.g., where the UWKA flew through the gravity wave between 0 and $10 \mathrm{~km}$ ). In the two regions where distinct fallstreaks are crossed, the 2DP and Nevzorov probes measure peaks in ice concentration and ice water content.
There is little to no associated peak in $\mathrm{LWC},{ }^{2}$ indicating that any liquid formation evaporated or was consumed by ice during the previous $20-25 \mathrm{~min}$, before the fallstreak reached flight level.

More broadly, there is a continuous layer of enhanced reflectivity parallel, and beneath, the layer of $\mathrm{KH}$ instability on this flight leg (Fig. 6a, in the range $10<x<45 \mathrm{~km}$ at $5 \mathrm{~km}$ MSL) and in other flight legs (Fig. 4 in Part I), within a temperature range of $-14^{\circ}$ to $-8^{\circ} \mathrm{C}$ (according to proximity

\footnotetext{
${ }^{2}$ The steady low LWC values measured by the Nevzorov probe (Fig. 6c) are likely a small response to ice particles. The CDP and Rosemount probes both show no liquid present.
} 


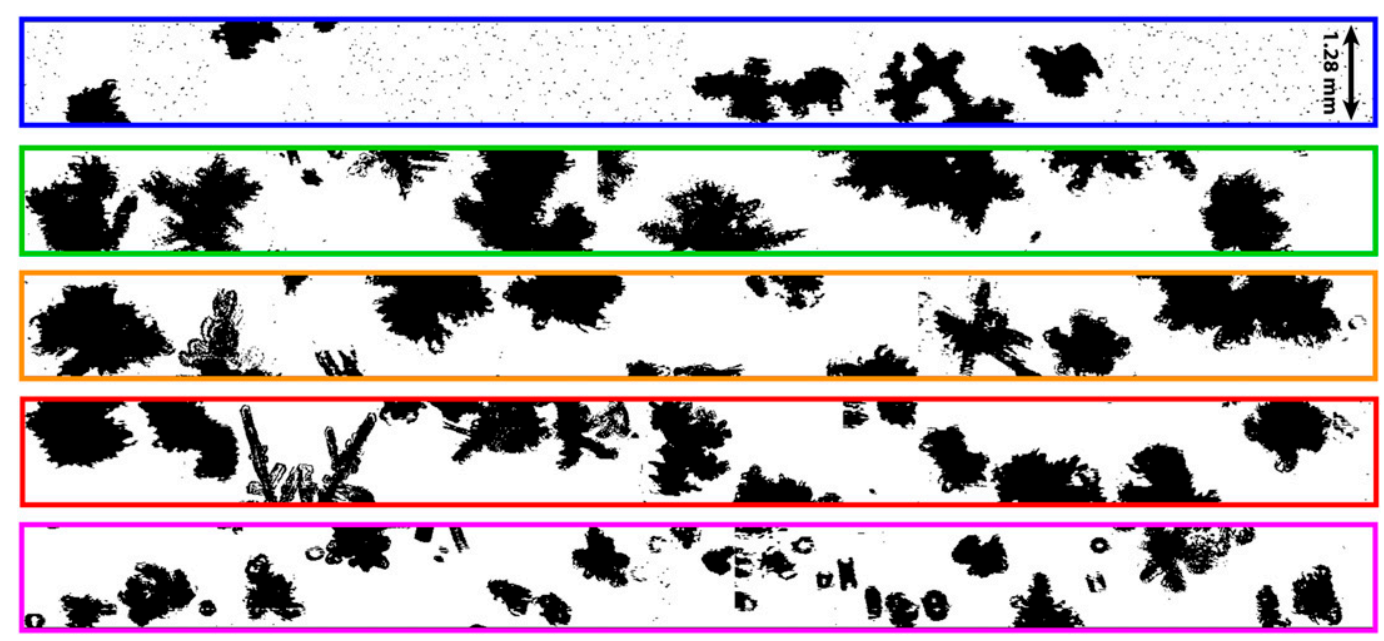

FIG. 7. 2DS particle images during the transect in Fig. 6. Colored boxes correspond to regions of matching colored lines in Fig. 6e.

sounding data). The primary fallstreaks appear to contribute to this enhanced reflectivity layer near flight level. Below this layer, reflectivity decreases until the melting layer, seen as a horizontal bright band. In this case, it seems that the $\mathrm{KH}$ wave activity enhances snow growth by deposition, resulting in larger crystals (Fig. 6e). While changes in the mean-volume diameter $^{3}$ estimate reflect changes in the number of large particles due to the larger particles' contribution to volume, changes in the mean diameter estimate are more sensitive to changes in the number of small particles (especially cloud droplets, which are much more numerous when present). Within the $\mathrm{KH}$ wave fallstreaks, local maxima in the mean diameter indicate a reduction in cloud droplets. A local minima in mean-volume diameter is surprising, as it suggests a decrease in larger ice particles, although it is still larger than regions downstream without $\mathrm{KH}$ waves. The PSD for the fallstreaks (not shown) does have fewer particles (compared to the surrounding regions) in the last few bins but more large particles (e.g., $0.5-4.0 \mathrm{~mm}$ ) overall.

The 2DS images from this transect reveal that the ice particles beneath the $\mathrm{KH}$ waves can reach larger aggregate sizes (Fig. 7). At the beginning of the transect $(0<x<7 \mathrm{~km}$, Fig. 6$)$, most of the particles are small liquid drops and most of the ice particles have been rimed as a result of the leading gravity wave (blue area). The region of larger reflectivity beneath the $\mathrm{KH}$ waves begins near $x=15 \mathrm{~km}$ corresponding to the large particles within the green box in Fig. 7 as well as slightly enhanced IWC and ice concentrations. The small $\mathrm{KH}$ waves above this region do not have individual fallstreaks (at least at this time) but we suspect that the increase in turbulence of the layer is responsible for the increase in reflectivity. The flight

\footnotetext{
${ }^{3}$ The mean-volume diameter is defined as the fourth moment of diameter $\left[\Sigma\left(N D^{4}\right)\right]$ divided by the third moment $\left[\Sigma\left(N D^{3}\right)\right]$, proportional to the total spherical volume), where $N$ is bin number concentration.
}

section through the discrete $\mathrm{KH}$ wave fallstreaks $(29<x<$ $38 \mathrm{~km}$, orange and red regions) encounters numerous ice particles, composed of dendrites and large aggregates. Between $53<x<58 \mathrm{~km}$ (Fig. 6, corresponding to the magenta line), the ice crystals are smaller and more pristine with some columns and dendrites identifiable (Fig. 7, magenta box). In summary, the region beneath the $\mathrm{KH}$ waves (including the $\mathrm{KH}$ fallstreaks) is characterized by increased ice concentrations composed of large aggregates when compared to the rest of the cloud transect. While large aggregates are consistent with turbulent collisions, the additional ice particles could be a result of collision fragmentation, droplet shattering (if the updrafts above contain liquid drops), and activation from transient supersaturation (Field et al. 2017; Korolev and Leisner 2020).

\section{d. Case 4: Bulk characteristics beneath fallstreaks}

The next case, from SNOWIE IOP-11 (4 February 2017), contains several fallstreaks with reflectivity enhancements of about $7 \mathrm{~dB}$ above background levels (Fig. 8a) descending from cloud-top $\mathrm{KH}$ waves (the region below flight level is not shown). Each of six serried rotors (shown schematically in Figs. 8a and $8 \mathrm{~b}$ with black clockwise arrows) appear to be the source of a clearly defined fallstreak (marked by purple arrows in Fig. 8a) and are contrasted with a region downstream without $\mathrm{KH}$ waves. These are not cloud-top generating cells, as evident by comparison with detailed WCR-based studies of such cells using the PLOWS dataset (e.g., Rauber et al. 2014, 2015; Plummer et al. 2015): cloud-top generating cells have their strongest vertical motions within a few $100 \mathrm{~m}$ from cloud top and appear driven by buoyancy (Keeler et al. 2016).

WCR observations combined with nearby sounding data suggest that this a $\mathrm{KH}$ wave train: vertical velocity patterns (Fig. 8b) match expectations presented in a conceptual diagram (Fig. 11 in Part I). Regular updrafts and downdrafts emanate from a layer of fine-scale turbulence driven by shear and dynamic overturning. Wavelike vertical velocity variations 


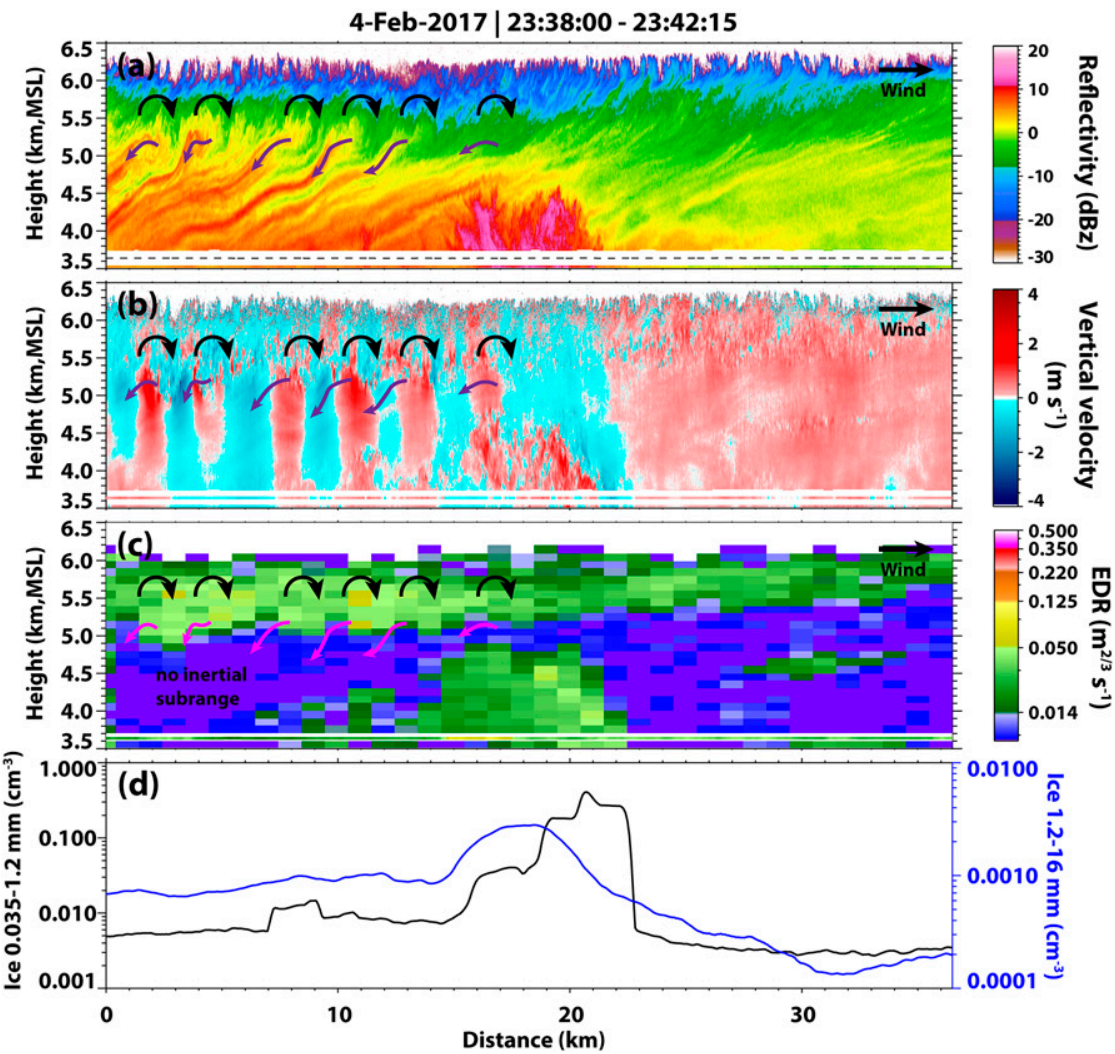

FIG. 8. (a),(b) As in Figs. 3 and 6, but for SNOWIE IOP-11 on 4 Feb 2017 zoomed in to the region of the cloud above flight level; (b) energy dissipation rate (EDR) derived from WCR vertical velocity, together with EDR measured at flight level (3.6 km MSL); and (d) counts of ice particles with diameters between 0.035 and $1.2 \mathrm{~mm}$ (black) and counts of ice particles with diameters between 1.2 and $16 \mathrm{~mm}$ (blue). Overturning $\mathrm{KH}$ billows are marked by black clockwise arrows and fallstreaks are marked by purple arrows.

above the overturning layer are missing, but that may simply be because of the lack of radar echoes. Sounding data for this case (not shown) reveal two strongly sheared stable layers with critical Richardson numbers near or below 0.25 .

The fallstreaks are tilted by the wind shear (the shear vector is pointed left to right) and appear sinuous because of the gravity waves that evanesce below the $\mathrm{KH}$ overturning layer. Where hydrometeors encounter an updraft, the fallstreak becomes horizontal, but hydrometeors are accelerated downward in regions of downdrafts, increasing the fallstreak slope. Significant snow growth (reflectivity increase) occurs in the turbulent region (between the purple and black arrows). The fallstreaks then descend from right to left, as highlighted by the purple arrows in Figs. $8 \mathrm{a}$ and $8 \mathrm{~b}$. As the fallstreaks pass through the gravity waves, there is no noticeable effect on reflectivity, indicating their benign impact when compared to the turbulent region above. Like the first case, this shows that turbulent mixing likely plays an important role in the formation of the $\mathrm{KH}$ wave fallstreaks.

$\mathrm{KH}$ waves are unique in that they produce both coherent eddies, with regular phase relationships, and incoherent turbulence, where high EDR (Fig. 8c) values exist. The updrafts of large, coherent eddies span distances that allow substantial supersaturation (mainly with respect to ice) increases resulting in enhanced vapor deposition and condensation. This naturally primes the environment for efficient collision-coalescence and accretion in the smaller-scale, incoherent turbulence that develops upon the breaking of $\mathrm{KH}$ billows.

Flight level $\left(3.6 \mathrm{~km} \mathrm{AGL} ;-11^{\circ} \mathrm{C}\right)$ is about $2 \mathrm{~km}$ below the overturning billows on this transect, and largely below the KHinduced gravity waves. In situ measurements indicate that this is an ice-dominated mixed-phase cloud, with small amounts of LWC $\left(<0.1 \mathrm{~g} \mathrm{~m}^{-3}\right)$. At this level, the fallstreaks have largely merged, or have been advected out of the transect. Large ice particles are more numerous in the region with $\mathrm{KH}$ waves $(0<$ $x<14 \mathrm{~km})$ compared to the region without $\mathrm{KH}$ waves $(24<$ $x<37 \mathrm{~km}$ ) as shown in Fig. 8d. The average number of small ice particles (diameters between 0.035 and $1.2 \mathrm{~mm}$ ) is $7.6 \mathrm{~L}^{-1}$ beneath the $\mathrm{KH}$ waves (black line). This is over 2 times greater than the average in the region without $\mathrm{KH}$ waves which has an average of $3.2 \mathrm{~L}^{-1}$. Similarly, the average number of large ice particles (diameters $>1.2 \mathrm{~mm}$ ) is 4 times larger beneath the KH waves: $0.8 \mathrm{~L}^{-1}$ compared to $0.2 \mathrm{~L}^{-1}$ (blue line). The total ice water content is 4 times greater beneath the $\mathrm{KH}$ waves, 

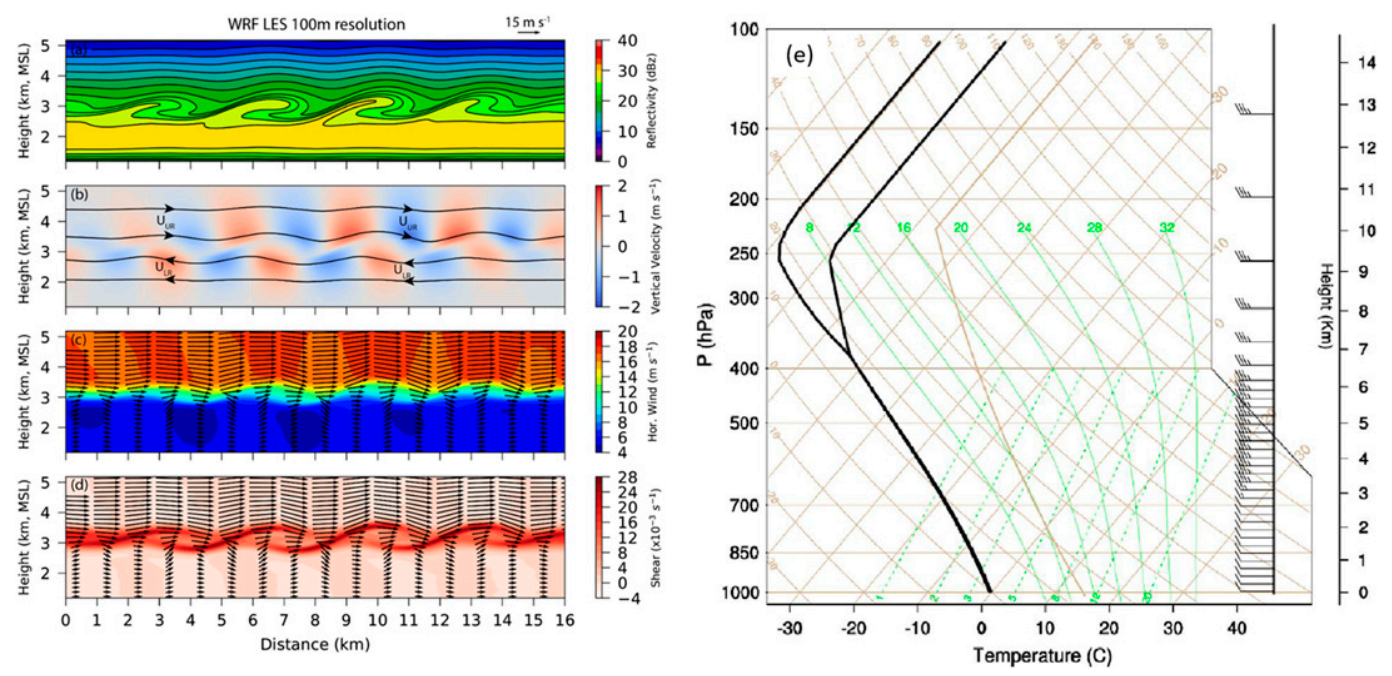

FIG. 9. KH waves from the LES model at the time of the greatest vertical velocity perturbations. Panels show (a) reflectivity, (b) air vertical velocity, (c) horizontal wind and 2D vectors, and (d), vertical shear and 2D vectors. (e) The profile used to initialize the model. The streamlines in (b) show the flow relative to the KH wave train above $\left(U_{\mathrm{UR}}\right)$ and below $\left(U_{\mathrm{LR}}\right)$ the instability layer.

$0.08 \mathrm{~g} \mathrm{~m}^{-3}$ compared to the downwind region with $0.02 \mathrm{~g} \mathrm{~m}^{-3}$ (not shown). The penetrating embedded convection near $x=$ $20 \mathrm{~km}$ is ignored in this discussion.

The temperature is about $-27^{\circ} \mathrm{C}$ at cloud top $(\sim 6.1 \mathrm{~km})$ and about $-22^{\circ} \mathrm{C}$ at the level of intense updrafts and strong turbulence $(\sim 5.3 \mathrm{~km})$. No in situ measurements are available at the KH wave level, but Plummer et al. (2014) showed that similar updrafts, found in cloud-top generating cells, can cause primary ice initiation and rapid depositional growth at similar temperatures, likely due to significant supersaturation relative to ice.

\section{Further insights into microphysical processes from an LES}

WCR radar profiles and dual-Doppler synthesis provide a clear depiction of the $\mathrm{KH}$ wave kinematics in stratiform precipitating clouds. Alone and combined with flight-level cloud probe data, WCR reflectivity data also illustrate how KH wave trains may affect snow growth and sedimentation in these examples, each with its own cloud and temperature characteristics. Because $\mathrm{KH}$ waves are too unpredictable and transient to be targeted directly with a research aircraft, passes directly through the level of $\mathrm{KH}$ instability are rare. Thus, in situ observations of $\mathrm{KH}$ waves are also limited, both in quantity and variety. Furthermore, there is an inherent complication when analyzing $\mathrm{KH}$ waves over complex terrain: while terrain-driven gravity waves often trigger $\mathrm{KH}$ instability, any $\mathrm{KH}$ waves may then be collocated with gravity wave updrafts, confounding the pure $\mathrm{KH}$ wave microphysical response.

Therefore, to better understand the microphysical processes that drive the precipitation enhancement seen in radar and in situ observations within and beneath $\mathrm{KH}$ waves, we employ an idealized cloud-resolving LES, to quantify what microphysical processes occur within and below the waves in the absence of terrain. The purpose of this simulation is to understand snow growth by observing the simulated mass conversions between vapor, liquid, and ice. The simulation is not designed to gain insight in ice initiation in $\mathrm{KH}$ waves. Although these processes are not independent, our model was not set up to allow ice initiation within the $\mathrm{KH}$ billows in any way other than what is captured in the Thompson cloud microphysics scheme (Thompson et al. 2008), which initiates ice as a function of temperature and supersaturation.

Several studies have used full-physics, nonidealized NWP models to simulate KH waves (e.g., Mahalov et al. 2011; Trier et al. 2012; Conrick et al. 2018), but the waves simulated in these studies were relatively large compared to ones observed here. The finest grid, the one used in Conrick et al. (2018), had a resolution of $444 \mathrm{~m}$, which is too coarse to resolve the fine structure of the KH waves described herein. To simulate the observed waves, we use the WRF LES framework at $100 \mathrm{~m}$ horizontal and 50-m vertical resolution with an idealized sounding and simplified physics (described in section $2 \mathrm{~d}$ ) to better capture the dynamical details of $\mathrm{KH}$ waves and explore their impact on snow growth.

Figures $9 \mathrm{a}-\mathrm{d}$ show the kinematics of a $\mathrm{KH}$ wave train embedded in a precipitating stratiform cloud within the LES model. Snow growth and sedimentation is transient in this simulation and is driven by an initially quasi-saturated deep layer (98\% RH relative to liquid water) (Fig. 9e), not by a sustained basic-state updraft. Reflectivity billows (Fig. 9a) align with coherent up- and downdrafts (Fig. 9b). The overturning regions are visible in Figs. $9 \mathrm{c}$ and $9 \mathrm{~d}$ as an intermediate wind speed and a braided shear structure that appears very similar to WCR observations (e.g., Fig. 9 in Part I). The KH waves in this simulation are not triggered by terrain, as in Sauer et al. (2016) (our model terrain is flat), but by a highly sheared 
stable layer in an upstream idealized sounding (Fig. 9e): a weakly stable layer with equivalent potential temperature increasing at $1 \mathrm{~K} \mathrm{~km}^{-1}$ existed from the surface to $7 \mathrm{~km}$. From $7 \mathrm{~km}$ to the tropopause $(250 \mathrm{mb})$, the temperature decreases at $6.5 \mathrm{~K} \mathrm{~km}^{-1}$ and the relative humidity decreases. A shear layer is defined between 2.3 and $2.8 \mathrm{~km}$ although this layer lifted slightly with time. In this layer, the westerly wind increases with height from 5 to $17 \mathrm{~m} \mathrm{~s}^{-1}$. The wind speed remains constant above $2.75 \mathrm{~km}$. The Richardson number in the shear layer is initially 0.06 , well below the theoretical threshold for $\mathrm{KH}$ instability to be released $(\mathrm{Ri}=0.25)$. Weaker $\mathrm{KH}$ waves occurred in an identical simulation with weaker shear $(\mathrm{Ri}=0.07)$ and even weaker ones for $\mathrm{Ri}=0.08$.

Ideally, to evaluate the impact of $\mathrm{KH}$ waves on cloud and precipitation, a simulation with vertical wind shear strong enough to produce $\mathrm{KH}$ billows should be contrasted with a simulation with vertical wind shear just too low to produce $\mathrm{KH}$ billows, but otherwise is the same. However, there is no such wind shear threshold that separates the formation of $\mathrm{KH}$ billows. A slightly weaker wind shear will still produce overturning cells, but with much weaker vertical velocity. A dramatic change in wind shear is required to distinguish the simulation with $\mathrm{KH}$ billows against one with no billows at all. Such change in wind shear also alters the cloud dynamics and results in a redistribution of the surface precipitation. To isolate the microphysical impact of $\mathrm{KH}$ billows, we compare the strong wind shear case $(\mathrm{Ri}=0.06)$ with pronounced overturning cells, i.e., strong KH billows (SKH), shown in Fig. 9, against a slightly weaker wind shear case $(\mathrm{Ri}=0.07)$ with much weaker overturning cells (WKH). The wind shear difference between the two cases is so small that it does not significantly affect background cloud dynamics.

The simulated $\mathrm{KH}$ waves (SKH) occur in a mixed-phase cloud, well below cloud top. The cloud top, initially at $T=-55^{\circ} \mathrm{C}$, descends throughout the simulation period along with the precipitating snow. Forty-five minutes into the simulation, the layer with snow (large, precipitating ice) is within the shear layer with an active $\mathrm{KH}$ wave train (Fig. 10), where the temperature was around $T=-20^{\circ} \mathrm{C}$. Liquid cloud is sustained or even enhanced in updrafts; however, the downdrafts cause the liquid to evaporate (Fig. 10b). Ice extends above the liquid cloud region because the relative humidity was larger for ice than for liquid (i.e., ice has a lower saturation vapor pressure than liquid). Another result of this is that the ice persists through the overturning billow where liquid does not (Figs. 10b,c, circled regions). Any precipitation enhancements, therefore, are likely associated with snow growth (deposition + accretion) and fallout. The model output confirms that the perturbations of ice + snow mass are larger than those of cloud water mass (not shown).

We now analyze the cloud processes contributing to snow growth, as parameterized by the Thompson scheme, in Fig. 11, in the context of the vertical velocity couplets and snow anomalies (top two panels). In this figure, any anomaly in the SKH case is a perturbation from the WKH case. Comparing all snow growth mechanisms, only vapor deposition (Fig. 11d) and accretion (snow collecting water) (Fig. 11c) shows appreciable quantities. Other snow growth mechanisms are either invariant or more than an order of magnitude smaller (not shown).
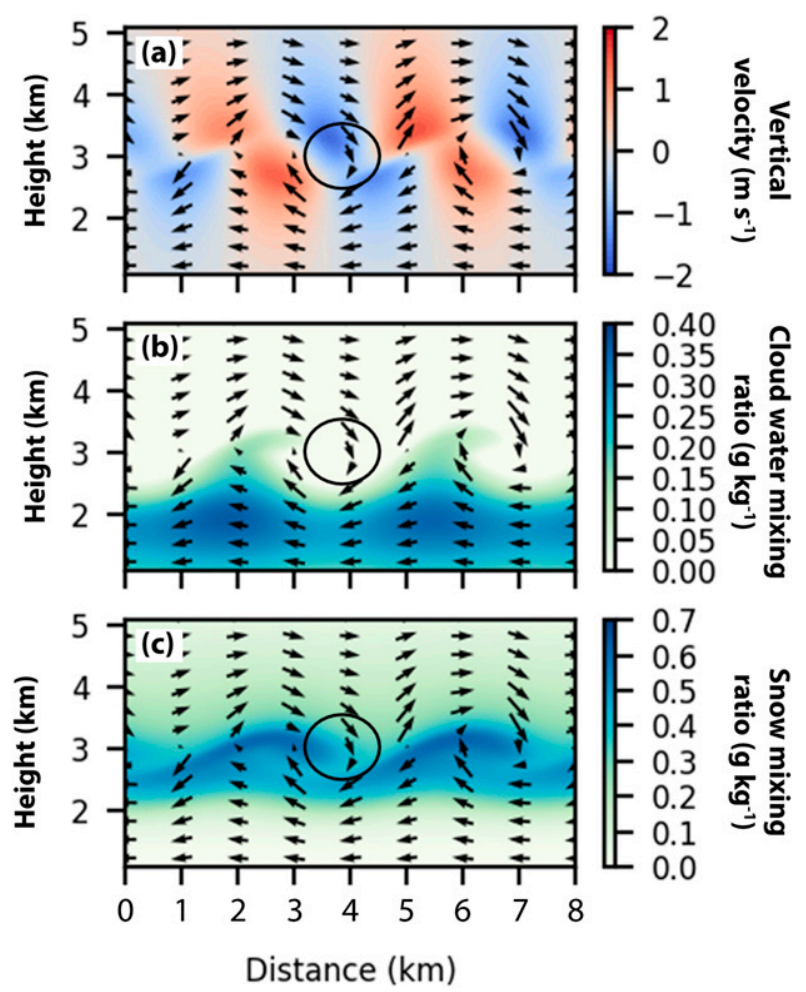

FIG. 10. (a) Model vertical velocity, (b) cloud water mixing ratio, and (c) snow water mixing ratio at $45 \mathrm{~min}$.

Where cloud liquid content is enhanced beneath a billow updraft (Fig. 10b), snow grows by accreting water (Fig. 11c). Additionally, snow growth by deposition is enhanced at the crest of a billow where ice supersaturation is largest (larger water vapor content + lower temperature, Fig. 11d). This growth region extends outside the liquid region due to vapor deposition (ice saturation) supported by evaporating liquid that had not been lost by accretion.

In summary, the LES shows that snow growth can be enhanced by vapor deposition and accretion in the $\mathrm{KH}$ updrafts. Comparing average vertical profiles of cloud water shows that $\mathrm{KH}$ waves increase cloud water at the KH wave level [Figs. 12a(1),a(2)] due to more vigorous condensation rates within the SKH updrafts. The liquid cloud water contributes to snow growth via accretion [Figs. 12d(1),d(2)]. Evaporation aloft [Fig. 12c(2)] comes from the cloud-top detrainment and evaporation of cloud liquid water transported upward by the eddies. The additional depositional growth is smaller than the sublimation in the downward eddies [Fig. 12e(2)] but is compensated for by the additional accretion. Overall, the SKH case produces $1 \%$ more precipitation on the ground than the WKH case. This value is small (since we are contrasting two KH wave cases of different strength), but indicates that the net effect of a $\mathrm{KH}$ wave train is positive. In the sequence of up- and downdrafts in the wave train, there is net snow growth because the snow growth in the crests exceeds snow sublimation in the troughs and is related to the saturation vapor pressure difference between water and ice. This net snow growth may be offset by 

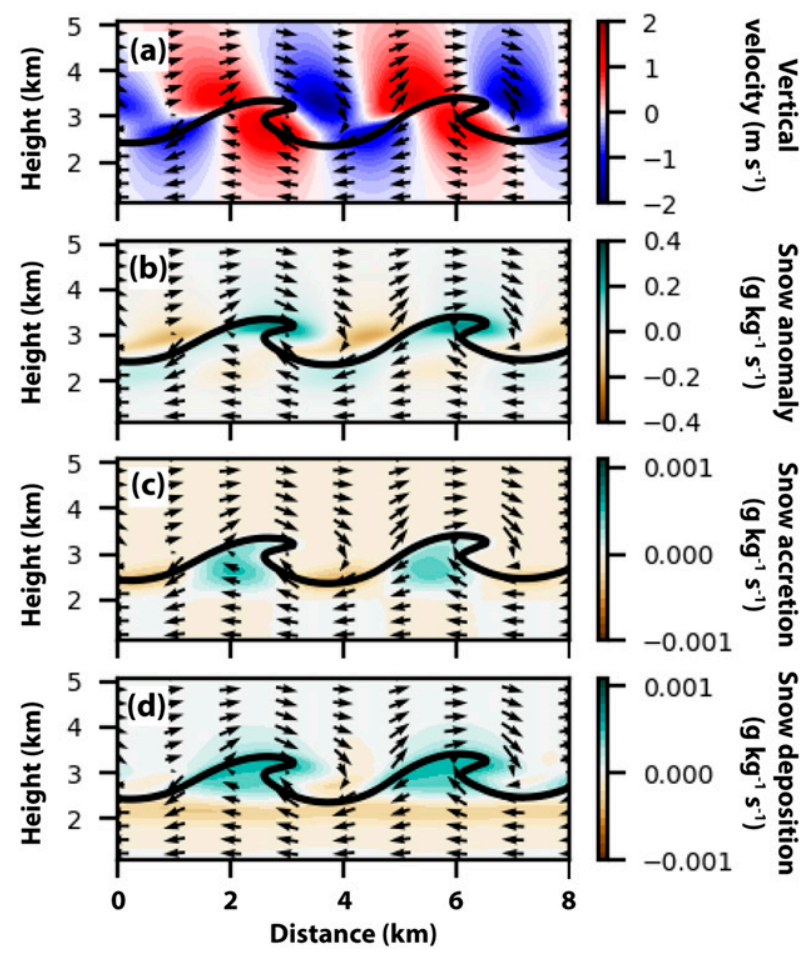

FIG. 11. (a) Model vertical velocity from the SKH case and difference fields (SKH - WKH) indicating the growth or loss of snow resulting in the (b) snow anomaly. These include (c) snow accretion and (d) snow deposition. Other paths for snow growth were negligible.

enhanced sublimation due to entrainment of drier air if the $\mathrm{KH}$ billows are near the cloud edge, as is the case later on in this simulation, when the cloud top descends to the shear layer.

\section{Discussion}

Observational evidence provided herein indicates that $\mathrm{KH}$ waves can induce microphysical changes that initiate ice and enhance hydrometeor sizes and/or concentrations. While the $\mathrm{KH}$ wave train cases illustrated here are generally marked by reflectivity enhancements, our collection of $\mathrm{KH}$ wave cases from CAMPS and SNOWIE also contain many mostly lowamplitude $\mathrm{KH}$ wave trains with little or no apparent change in the reflectivity field. Under some circumstances, $\mathrm{KH}$ waves may be detrimental to cloud and precipitation. For example, this may occur when $\mathrm{KH}$ waves are near cloud top, increasing entrainment/detrainment. Such cloud-top cases were present in SNOWIE and CAMPS but are difficult to detect and analyze because of inadequate radar returns. Because it is difficult to prove a negative effect (i.e., the reduction of reflectivity due to entrainment) based on the lack of reflectivity, especially with only periodic "snapshots" in time, we do not investigate these cases.

Furthermore, whether the overturning billows of KH waves benefit precipitation formation and fallout likely depends on temperature, cloud phase distribution (liquid or ice dominated),
$\mathrm{KH}$ wave size/turbulence, and location relative to cloud edge and terrain-induced vertically propagating gravity waves. For example, a cloud with low ice concentrations that is kinetically limited (i.e., the increasing saturation cannot be offset by deposition) will condense liquid within updrafts. A less kinetically limited cloud will require larger updrafts from larger (deeper) $\mathrm{KH}$ billows. However, our observational and modeling datasets did not allow for an investigation into these variables.

The WCR observations in case 3 (SNOWIE IOP-11; Fig. 8) suggest that the $\mathrm{KH}$ waves may be important in primary ice initiation, possibly due to the large ice supersaturation in the updrafts, and the production of liquid water for immersion and/or contact freezing seen in case 2 (e.g., CAMPS IOP-09; Fig. 3). In the Thompson scheme (Thompson et al. 2008), primary ice nucleation depends on both temperature and supersaturation, while heterogeneous freezing of water droplets depends on temperature only. In the simulations of transient precipitation growth and fallout shown here, ice nucleation occurred earlier, at a level well above the shear layer, so these simulations do not address the possible relevance of $\mathrm{KH}$ billows in ice initiation. Under suitable temperatures, $\mathrm{KH}$ billows may impact secondary ice initiation as well, since they generate pockets of high LWC (Fig. 10b), but that too is not addressed in the LES.

In addition, the 100-m LES is unable to resolve the fine-scale turbulence discussed in the preceding section, or the microphysical effects of such turbulence. Without breaking into turbulence, the $\mathrm{KH}$ waves in the SKH run do not significantly affect snow growth and precipitation. Any gain in condensation or deposition in updrafts is nearly offset by evaporation and deposition in downdrafts (Fig. 12), resulting in only small increases in cloud and snow mixing ratios.

\section{Conclusions}

In-cloud Kelvin-Helmholtz (KH) waves are commonly present in stratified precipitation systems above complex terrain, often with enhanced radar reflectivity fallstreaks descending from the region of turbulent overturning. Airborne cloud radar and in situ microphysics data presented here from the CAMPS 2011 field campaign in Colorado and the SNOWIE 2017 campaign in Idaho indicate that $\mathrm{KH}$ waves can substantially alter cloud processes and precipitation.

Our results support the following conclusions:

- The fallstreaks show qualitatively that the vertical velocity couplets and turbulent mixing associated with $\mathrm{KH}$ waves may enhance orographic precipitation. When liquid water is present, ice mass can increase, mainly due to depositional and accretional growth in regions of water supersaturation created by updrafts. Differential terminal velocities produce particle collisions. The addition of turbulence increases the number of collisions and the rate of snow growth. Due to the common occurrence of $\mathrm{KH}$ waves, it is suspected that $\mathrm{KH}$ waves play a role in orographic precipitation systems affecting hydrometeor size distributions, phase partitioning, and fallout, but quantitatively, their importance remains an open question.

- KH wave updrafts can increase, or introduce, cloud liquid water. In overturning $\mathrm{KH}$ billows sampled by flight-level 

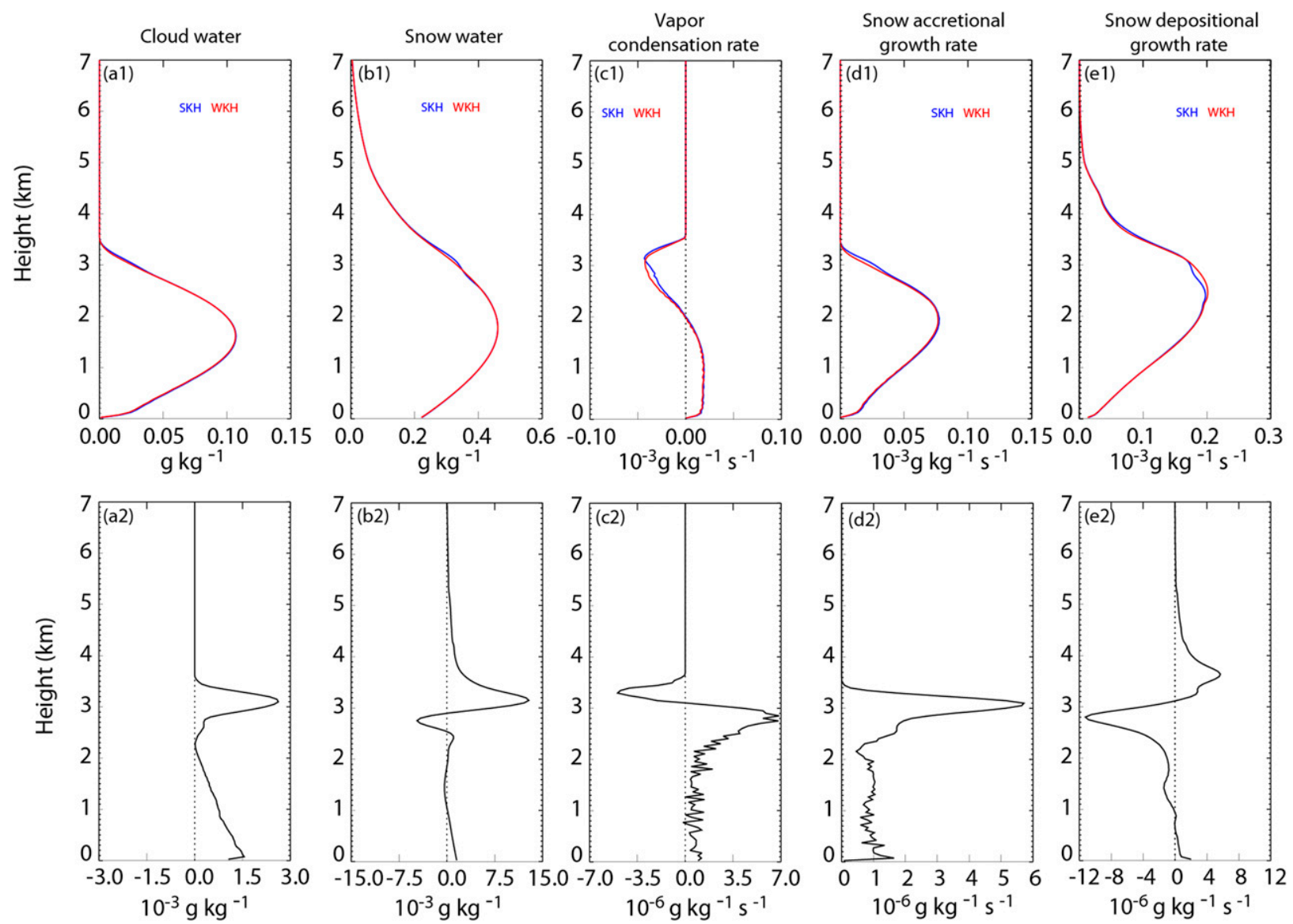

FIG. 12. (top) Domain- and time-averaged vertical profiles of $[\mathrm{a}(1)]$ cloud water mixing ratio, $[\mathrm{b}(1)]$ snow mixing ratio, [c(1)] vapor condensation rate, $[\mathrm{d}(1)]$ snow depositional growth rate, and $[\mathrm{e}(1)]$ snow accretional growth rate. (bottom) Corresponding differences between SKH and WKH cases. Profiles are averaged in a moving domain following the KH waves.

probes, secondary activation of liquid droplets was observed in mixed-phase cloud in response to repeated supersaturation fluctuations. Observed (section 3) and simulated (section 4, Fig. 10a) KH waves show that the largest vertical velocity perturbations and liquid enhancement are within the overturning billows. The LES model resolves these billows (i.e., large-scale eddies), and their effects on microphysical processes, showing that the largest precipitation enhancement within a mixed-phase cloud is by accretion and deposition (Fig. 11) and results in a net enhancement of snow mixing ratio [Fig. 12b(2)].

- KH waves can increase ice number concentration. When flying beneath $\mathrm{KH}$ waves, optical array probe data indicate higher concentrations of ice when compared to other regions of the cloud without $\mathrm{KH}$ waves. The driving mechanism for this increase is unclear from our data. While increasing liquid causes ice growth via accretion, our data indicate that another mechanism is at work such as nucleation of additional ice or fragmentation from enhanced collisions.

- The small-scale turbulence within breaking $\mathrm{KH}$ waves may be important for developing the observed fallstreaks, since these streaks can be traced back to individual radarobserved breaking waves and turbulence (Figs. 2a, 6a, and 8a).
Furthermore, fallstreaks did not form in an LES model which is too coarse to resolve small-scale turbulence.

Additional $\mathrm{KH}$ wave research should focus on determining how and under what conditions $\mathrm{KH}$ waves impact cloud and precipitation processes. This a complex problem, best addressed through a combined use of observations and models, including sensitivity studies capturing the full parameter space of temperatures and concentrations of cloudactive nuclei, ice, and liquid, as suggested by observations. A significant challenge will be the simulation/parameterization of the effects of the small-scale turbulence from breaking $\mathrm{KH}$ waves.

Acknowledgments. We are grateful to Adam Majewski for help with processing OAP data and to Troy Zaremba for testing corrections to the WCR vertical velocity. We also want to acknowledge the efforts of the principal investigators during CAMPS (Gannet Hallar, Douglas Lowenthal, Linnea Avallone, and Matthew Shupe) and SNOWIE (Jeff French, Sarah Tessendorf, Roy Rasmussen, Katja Friedrich, Bart Geerts, and Robert Rauber). This study was funded by the National Science Foundation Grants AGS-1546939, AGS-2016106, AGS-1547101, and AGS-2016077. Funding for the deployment of the University 
of Wyoming King Air in SNOWIE and CAMPS was funded by AGS-1441831 and AGS-0832637.

Data availability statement. Data collected during the SNOWIE Campaign are available to the public from the Earth Observing Laboratory data archive hosted by the National Center for Atmospheric Research. Balloon sounding data can be accessed at https://doi.org/10.5065/D67S7MJ9 (Blestrud 2018). Flight level aircraft measurements can be retrieved from https://doi.org/10.15786/M2MW9F (University of Wyoming Research Flight Center 2017a) and WCR data can be retrieved from https://doi:10.15786/M2CD4J (University of Wyoming Research Flight Center 2017b). CDP and OAP size spectra data can be accessed at https://doi.org/10.5065/D6GT5KXK (French and Majewksi 2017).

\section{REFERENCES}

Barnes, H. C., J. P. Zagrodnik, L. A. McMurdie, A. K. Rowe, and R. A. Houze Jr., 2018: Kelvin-Helmholtz waves in precipitating midlatitude cyclones. J. Atmos. Sci., 75, 2763-2785, https://doi.org/10.1175/JAS-D-17-0365.1.

Bergeron, T., 1935: On the physics of cloud and precipitation. Proc. Fifth Assembly UGGI, Lisbon, Portugal, Union Géodésique et Géophysique Internationale, 156-178.

Bergmaier, P. T., and B. Geerts, 2016: Airborne radar observations of lake-effect snow bands over the New York Finger Lakes. Mon. Wea. Rev., 144, 3895-3914, https://doi.org/10.1175/MWRD-16-0103.1.

Blestrud, D., 2018: Idaho Power Company Crouch sounding data [IPC], version 1.0. UCAR/NCAR Earth Observing Laboratory, accessed 16 January 2018, https://doi.org/10.5065/D67S7MJ9.

Chen, S., P. Bartello, M. K. Yau, P. A. Vaillancourt, and K. Zwijsen, 2016: Cloud droplet collisions in turbulent environment: Collision statistics and parameterization. J. Atmos. Sci., 73, 621-636, https://doi.org/10.1175/JAS-D-15-0203.1.

Choularton, T. W., and S. J. Perry, 1986: A model of the orographic enhancement of snowfall by the seeder-feeder mechanism. Quart. J. Roy. Meteor. Soc., 112, 335-345, https://doi.org/ 10.1002/qj.49711247204.

Chu, X., L. Xue, B. Geerts, and B. Kosovicì, 2018: The impact of boundary layer turbulence on snow growth and precipitation: Idealized large eddy simulations. Atmos. Res., 204, 54-66, https://doi.org/10.1016/j.atmosres.2018.01.015.

Conrick, R., C. F. Mass, and Q. Zhong, 2018: Simulated KelvinHelmholtz waves over terrain and their microphysical implications. J. Atmos. Sci., 75, 2787-2800, https://doi.org/10.1175/ JAS-D-18-0073.1.

Damiani, R., and S. Haimov, 2006: A high-resolution dual-Doppler technique for fixed multiantenna airborne radar. IEEE Trans. Geosci. Remote Sens., 44, 3475-3489, https://doi.org/10.1109/ TGRS.2006.881745.

Field, P. R., and Coauthors, 2017: Secondary ice production: Current state of the science and recommendations for the future. Ice Formation and Evolution in Clouds and Precipitation: Measurement and Modeling Challenges, Meteor. Monogr., No. 58, Amer. Meteor. Soc., https://doi.org/10.1175/AMSMONOGRAPHSD-16-0014.1.

Finlon, J. A., G. M. McFarquhar, R. M. Rauber, D. M. Plummer, B. F. Jewett, D. Leon, and K. R. Knupp, 2016: A comparison of X-band polarization parameters with in situ microphysical measurements in the comma head of two winter cyclones.
J. Appl. Meteor. Climatol., 55, 2549-2574, https://doi.org/ 10.1175/JAMC-D-16-0059.1.

French, J. R., and A. Majewksi, 2017: UW King Air hydrometeor size spectra data, version 1.0. UCAR/NCAR Earth Observing Laboratory, accessed 22 December 2017, https://doi.org/10.5065/ D6GT5KXK.

- and Coauthors, 2018: Precipitation formation from orographic cloud seeding. Proc. Natl. Acad. Sci. USA, 115, 11681173, https://doi.org/10.1073/pnas.1716995115.

Friedrich, K., and Coauthors, 2020: Quantifying snowfall from orographic cloud seeding. Proc. Natl. Acad. Sci. USA, 117, 5190-5195, https://doi.org/10.1073/pnas.1917204117.

Geerts, B., and Q. Miao, 2005: The use of millimeter Doppler radar echoes to estimate vertical air velocities in the fair-weather convective boundary layer. J. Atmos. Oceanic Technol., 22, 225-246, https://doi.org/10.1175/JTECH1699.1.

_ R. Ramiani, and S. Haimov, 2006: Finescale vertical structure of a cold front as revealed by an airborne Doppler radar. Mon. Wea. Rev., 134, 251-271, https://doi.org/10.1175/MWR3056.1.

- Q. Miao, and Y. Yang, 2011: Boundary layer turbulence and orographic precipitation growth in cold clouds: Evidence from profiling airborne radar data. J. Atmos. Sci., 68, 2344-2365, https://doi.org/10.1175/JAS-D-10-05009.1.

Grabowski, W. W., and L. P. Wang, 2013: Growth of cloud droplets in a turbulent environment. Annu. Rev. Fluid Mech., 45, 293324, https://doi.org/10.1146/annurev-fluid-011212-140750.

Grasmick, C., and B. Geerts, 2020: Detailed dual-Doppler structure of Kelvin-Helmholtz waves from an airborne profiling radar over complex terrain. Part I: Dynamic structure. J. Atmos. Sci., 77, 1761-1782, https://doi.org/10.1175/JAS-D-19-0108.1.

Haimov, S., and A. Rodi, 2013: Fixed-antenna pointing-angle calibration of airborne Doppler cloud radar. J. Atmos. Oceanic Technol., 30, 2320-2335, https://doi.org/10.1175/JTECH-D12-00262.1.

Hallett, J., and S. C. Mossop, 1974: Production of secondary ice particles during the riming process. Nature, 249, 26-28, https:// doi.org/10.1038/249026a0.

Herzegh, P. H., and P. V. Hobbs, 1980: The mesoscale and microscale structure and organization of clouds and precipitation in midlatitude cyclones. II: Warm-frontal clouds. J. Atmos. Sci., 37, 597-611, https://doi.org/10.1175/1520-0469(1980)037<0597: TMAMSA $>2.0 . \mathrm{CO} ; 2$.

Houser, J. L., and H. B. Bluestein, 2011: Polarimetric Doppler radar observations of Kelvin-Helmholtz waves in a winter storm. J. Atmos. Sci., 68, 1676-1702, https://doi.org/10.1175/ 2011JAS3566.1.

Houze, R. A., Jr., and S. Medina, 2005: Turbulence as a mechanism for orographic precipitation enhancement. J. Atmos. Sci., 62, 3599-3623, https://doi.org/10.1175/JAS3555.1.

Jackson, R. C., and G. M. McFarquhar, 2014: An assessment of the impact of antishattering tips and artifact removal techniques on bulk cloud ice microphysical and optical properties measured by the 2D cloud probe. J. Atmos. Oceanic Technol., 31, 2131-2144, https://doi.org/10.1175/JTECH-D-14-00018.1.

Kalesse, H., W. Szyrmer, S. Kneifel, P. Kollias, and E. Luke, 2016: Fingerprints of a riming event on cloud radar Doppler spectra: Observations and modeling. Atmos. Chem. Phys., 16, 29973012, https://doi.org/10.5194/acp-16-2997-2016.

Keeler, J. M., B. F. Jewett, R. M. Rauber, G. M. McFarquhar, R. M. Rasmussen, L. Xue, C. Liu, and G. Thompson, 2016: Dynamics of cloud-top generating cells in winter cyclones. Part II: Radiative and instability forcing. J. Atmos. Sci., 73, 1529-1553, https://doi.org/10.1175/JAS-D-15-0127.1. 
Keppas, S. C., J. Crosier, T. W. Choularton, and K. N. Bower, 2018: Microphysical properties and radar polarimetric features within a warm front. Mon. Wea. Rev., 146, 2003-2022, https:// doi.org/10.1175/MWR-D-18-0056.1.

Korolev, A. V., 1995: The influence of supersaturation fluctuations on droplet size spectra formation. J. Atmos. Sci., 52, 3620-3634, https://doi.org/10.1175/1520-0469(1995)052<3620: TIOSFO $>2.0 . \mathrm{CO} ; 2$.

— relaxation in mixed clouds (theoretical consideration). Russ. Meteor. Hydrol., 28, 5-24.

secondary ice production. Atmos. Chem. Phys., 20, $11767-$ 11797, https://doi.org/10.5194/acp-20-11767-2020.

, J. W. Strapp, G. A. Isaac, and A. N. Nevzorov, 1998: The Nevzorov airborne hot-wire LWC-TWC probe: Principle of operation and performance characteristics. J. Atmos. Oceanic Technol., 15, 1495-1510, https://doi.org/10.1175/1520-0426(1998) $015<1495$ :TNAHWL $>2.0$. CO;2.

—, and Coauthors, 2017: Mixed-phase clouds: Progress and challenges. Ice Formation and Evolution in Clouds and Precipitation: Measurement and Modeling Challenges, Meteor. Monogr., No. 58, Amer. Meteor. Soc., https://doi.org/10.1175/ AMSMONOGRAPHS-D-17-0001.1.

Lance, S., C. A. Brock, D. Rogers, and J. A. Gordon, 2010: Water droplet calibration of a cloud droplet probe and in-flight performance in liquid, ice and mixed-phase clouds during ARCPAC. Atmos. Meas. Tech., 3, 1683-1706, https://doi.org/ 10.5194/amt-3-1683-2010.

Lawson, R. P., D. O'Connor, P. Zmarzly, K. Weaver, B. Baker, Q. Mo, and H. Jonsson, 2006: The 2D-S (stereo) probe: Design and preliminary tests of a new airborne, high-speed, highresolution particle imaging probe. J. Atmos. Oceanic Technol., 23, 1462-1477, https://doi.org/10.1175/JTECH1927.1.

Mahalov, A., M. Moustaoui, and V. Grubisic, 2011: A numerical study of mountain waves in the upper troposphere and lower stratosphere. Atmos. Chem. Phys., 11, 5123-5139, https:// doi.org/10.5194/acp-11-5123-2011.

Majewski, A., and J. R. French, 2020: Supercooled drizzle development in response to semi-coherent vertical velocity fluctuations within an orographic-layer cloud. Atmos. Chem. Phys., 20, 5035-5054, https://doi.org/10.5194/acp-20-5035-2020.

Mazin, I., 1986: Relation of cloud phase structure to vertical motion. Sov. Meteor. Hydrol., N11, 27-35.

Medina, S., and R. A. Houze, 2015: Small-scale precipitation elements in midlatitude cyclones crossing the California Sierra Nevada. Mon. Wea. Rev., 143, 2842-2870, https://doi.org/10.1175/MWR-D-14-00124.1.

Miao, Q., B. Geerts, and M. LeMone, 2006: Vertical velocity and buoyancy characteristics of coherent echo plumes in the convective boundary layer, detected by a profiling airborne radar. J. Appl. Meteor. Climatol., 45, 838-855, https://doi.org/10.1175/JAM2375.1.

Moeng, C. H., 1984: A large-eddy-simulation model for the study of planetary boundary-layer turbulence. J. Atmos. Sci., 41, 2052-2062, https://doi.org/10.1175/1520-0469(1984)041<2052: ALESMF $>2.0 . \mathrm{CO} ; 2$.

Murphy, A. M., R. M. Rauber, G. M. McFarquhar, J. A. Finlon, D. M. Plummer, A. A. Rosenow, and B. F. Jewett, 2017: A microphysical analysis of elevated convection in the comma head region of continental winter cyclones. J. Atmos. Sci., 74, 69-91, https://doi.org/10.1175/JAS-D-16-0204.1.

Pinsky, M., and A. Khain, 1998: Some effects of cloud turbulence on water-ice and ice-ice collisions. Atmos. Res., 47-48, 69-86, https://doi.org/10.1016/S0169-8095(98)00041-6.
,-- , and M. Shapiro, 1999: Collisions of small drops in a turbulent flow. Part I: Collision efficiency. Problem formulation and preliminary results. J. Atmos. Sci., 56, 2585-2600, https://doi.org/10.1175/1520-0469(1999)056<2585:COSDIA $>$ 2.0.CO;2.

,-- , and — 2000: Stochastic effects of cloud droplet hydrodynamic interaction in a turbulent flow. Atmos. Res., 53, 131-169, https://doi.org/10.1016/S0169-8095(99)00048-4.

Plummer, D. M., G. M. McFarquhar, R. M. Rauber, B. F. Jewett, and D. C. Leon, 2014: Structure and statistical analysis of the microphysical properties of generating cells in the comma head region of continental winter cyclones. J. Atmos. Sci., 71, 4181-4203, https://doi.org/10.1175/JASD-14-0100.1.

,,,---- , and,- 2015 : Microphysical properties of convectively generated fall streaks within the stratiform comma head region of continental winter cyclones. J. Atmos. Sci., 72, 2465-2483, https://doi.org/10.1175/JAS-D-14-0354.1.

Rauber, R. M., and A. Tokay, 1991: An explanation for the existence of supercooled water at the top of cold clouds. J. Atmos. Sci., 48, 1005-1023, https://doi.org/10.1175/1520-0469(1991) $048<1005$ :AEFTEO $>2.0 . \mathrm{CO} ; 2$

_- J. Wegman, and J. Plummer, 2014: Stability and charging characteristics of the comma head region of continental winter cyclones. J. Atmos. Sci., 71, 1559-1582, https://doi.org/10.1175/ JAS-D-13-0253.1.

— , and Coauthors, 2015: The role of cloud-top generating cells and boundary layer circulations in the finescale radar structure of a winter cyclone over the Great Lakes. Mon. Wea. Rev., 143, 2291-2318, https://doi.org/10.1175/MWR-D-14-00350.1.

Rosenow, A. A., D. M. Plummer, R. M. Rauber, G. M. McFarquhar, B. F. Jewett, and D. Leon, 2014: Vertical velocity and physical structure of generating cells and convection in the comma head region of continental winter cyclones. J. Atmos. Sci., 71, 15381558, https://doi.org/10.1175/JAS-D-13-0249.1.

Rutledge, S. A., and P. Hobbs, 1983: The mesoscale and microscale structure and organization of clouds and precipitation in midlatitude cyclones. VIII: A model for the "seeder-feeder" process in warm-frontal rainbands. J. Atmos. Sci., 40, 1185-1206, https://doi.org/10.1175/1520-0469(1983) $040<1185$ :TMAMSA $>2.0$. CO 2 .

Sauer, J. A., D. Muñoz-Esparza, J. M. Canfield, K. R. Costigan, R. R. Linn, and Y. Kim, 2016: A large-eddy simulation study of atmospheric boundary layer influence on stratified flows over terrain. J. Atmos. Sci., 73, 2615-2632, https://doi.org/ 10.1175/JAS-D-15-0282.1.

Tessendorf, S. A., and Coauthors, 2019: A transformational approach to winter orographic weather modification research: The SNOWIE project. Bull. Amer. Meteor. Soc., 100, 71-92, https://doi.org/10.1175/BAMS-D-17-0152.1.

Thompson, G., P. R. Field, R. M. Rasmussen, and W. D. Hall, 2008: Explicit forecasts of winter precipitation using an improved bulk microphysics scheme. Part II: Implementation of a new snow parameterization. Mon. Wea. Rev., 136, 5095-5115, https://doi.org/10.1175/2008MWR2387.1.

Trier, S. B., R. Sharman, and T. P. Lane, 2012: Influences of moist convection on a cold-season outbreak of clear-air turbulence (CAT). Mon. Wea. Rev., 140, 2477-2496, https://doi.org/ 10.1175/MWR-D-11-00353.1.

University of Wyoming Research Flight Center, 1995: University of Wyoming Cloud Radar (WCR). University of Wyoming College of Engineering, Dept. of Atmospheric Science, accessed 4 June 2020, https://doi.org/10.15786/M2237S. 
_ 2017a: Flight level data from the University of Wyoming King Air during the Seeded and Natural Orographic Wintertime clouds-the Idaho Experiment (SNOWIE) project, version 1.0. University of Wyoming College of Engineering, Dept. of Atmospheric Science, accessed 24 September 2020, https:// doi.org/10.15786/M2MW9F.

- 2017b: Wyoming cloud radar data from the University of Wyoming King Air during the University of Wyoming King Air during the Seeded and Natural Orographic Wintertime clouds-the Idaho Experiment (SNOWIE) project, version 1.0. University of Wyoming College of Engineering, Dept. of
Atmospheric Science, accessed 18 September 2020, https:// doi.org/10.15786/M2CD4J.

Wang, Z., and Coauthors, 2012: Single aircraft integration of remote sensing and in situ sampling for the study of cloud microphysics and dynamics. Bull. Amer. Meteor. Soc., 93, 653-668, https://doi.org/10.1175/BAMS-D-1100044.1.

Yamaguchi, T., and G. Feingold, 2012: Large-eddy simulation of cloudy boundary layer with the Advanced Research WRF Model. J. Adv. Model. Earth Syst., 4, M09003, https://doi.org/ 10.1029/2012MS000164. 